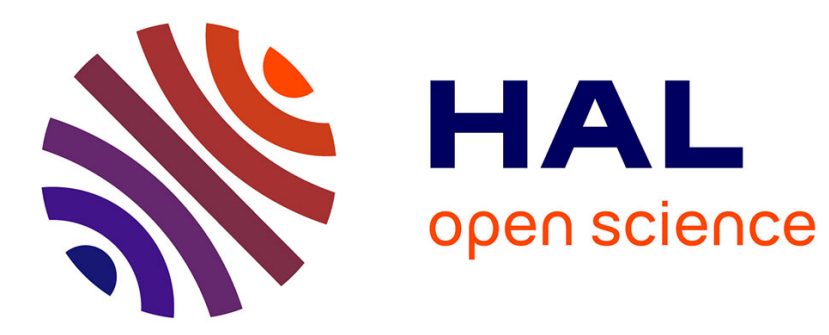

\title{
Preference Elicitation under Oath
}

Nicolas Jacquemet, Robert-Vincent Joule, Stephane Luchini, Jason Shogren

\section{To cite this version:}

Nicolas Jacquemet, Robert-Vincent Joule, Stephane Luchini, Jason Shogren. Preference Elicitation under Oath. Journal of Environmental Economics and Management, 2013, 65 (1), pp.110-132. 10.1016/j.jeem.2012.05.004 . halshs-00731244

\section{HAL Id: halshs-00731244 https://shs.hal.science/halshs-00731244}

Submitted on 12 Sep 2012

HAL is a multi-disciplinary open access archive for the deposit and dissemination of scientific research documents, whether they are published or not. The documents may come from teaching and research institutions in France or abroad, or from public or private research centers.
L'archive ouverte pluridisciplinaire HAL, est destinée au dépôt et à la diffusion de documents scientifiques de niveau recherche, publiés ou non, émanant des établissements d'enseignement et de recherche français ou étrangers, des laboratoires publics ou privés. 


\title{
Preference Elicitation under Oath ${ }^{1}$
}

\author{
Nicolas Jacquemet* Robert-Vincent Joule ${ }^{\dagger}$ \\ Stéphane Luchini ${ }^{\ddagger}$ Jason F. Shogren ${ }^{\S}$
}

June 2012

\begin{abstract}
Eliciting sincere preferences for non-market goods remains a challenge due to the discrepency between hypothetical and real behavior and false zeros. The gap arises because people either overstate hypothetical values or understate real commitments or a combination of both. Herein we examine whether the traditional real-world institution of the solemn oath can improve preference elicitation. Applying the social psychology theory on the oath as a truth-telling-commitment device, we ask our bidders to swear on their honour to give honest answers prior to participating in an incentive-compatible second-price auction. The oath is an ancillary mechanism to commit bidders to bid sincerely in a second-price auction. Results from our induced valuation testbed treatments suggest the oath-only auctions outperform all our other auctions (real and hypothetical). In our homegrown valuation treatments eliciting preferences for dolphin protection, the oath-only design induced people to treat as binding both their experimental budget constraint (i.e., lower values on the high end of the value distribution) and participation constraint (i.e., positive values in place of the zero bids used to opt-out of auction). Based on companion treatments, we show the oath works through an increase in the willingness to tell the truth, due to a strengthening of the intrinsic motivation to do so.
\end{abstract}

Keywords: $\quad$ Oath; Commitment; Vickrey auction; Hypothetical Bias;

Induced Values; Homegrown Values.

JEL Classification: C9; H4; Q5

*Paris School of Economics and University Paris I Panthéon-Sorbonne. Centre d'Economie de la Sorbonne, 106 Bd. de l'Hôpital, 75013 Paris. Nicolas.Jacquemet@univ-paris1.fr

${ }^{\dagger}$ Laboratoire de Psychologie Sociale - EA 849, University of Provence, 29, Avenue Robert-Schuman 13621 Aix-enProvence cedex 1. joule-rv@up.univ-aix.fr

${ }^{\ddagger}$ GREQAM-CNRS, Centre de la Vieille Charité, 13236 Marseille Cedex 02. stephane.luchini@univmed.fr

${ }^{\S}$ Corresponding author. Department of Economics and Finance, University of Wyoming, Laramie, WY 82071-3985, United States; and Department of Economics, Umeå University, S 90187 Umeå, Sweden. JRamses@uwyo.edu 
What gives an oath the degree of efficacy it possesses, is, that in most points, and with most men, a declaration upon oath includes a declaration upon honor: the laws of honor enjoining as to those points the observance of an oath. The deference shown is paid in appearance to the religious ceremony: but in reality it is paid, even by the most pious religionists, much more to the moral engagement than to the religious.

Jeremy Bentham, Rationale of judicial evidence (1827).

\section{Introduction}

Cost-benefit analysis is at the economic core of public policies devoted to the production of non-market goods. Eliciting sincere preferences to guide such cost-benefit analysis remains a challenge, however, due to the hypothetical bias - the gap between hypothetical monetary values and real economic commitments - and false zeros - people opt-out from the mechanism by stating a value equal to zero. Accumulating evidence from lab and field reveals the average person tends to overstate real economic commitments by a substantial amount $\mathrm{2}^{2}$ These results reinforce the long-standing explanation that the bias arises because the budget constraint is not binding in hypothetical valuation exercises (see Cummings, Brookshire, and Schulze, 1986, for a review). Other observers, however, have argued the opposite - real bids are "too low" as bidders shave bids downward, down to a "false zero" if they use the bid to exit the auction (Smith, 1994). Mechanism design requires the participation constraint to be bindingï $i \frac{1}{2}$ : i.e., a person should be no worse off by participating in the mechanism than otherwise (see for instance Laffont and Martimort, 2002). Most lab or field experiments, however, do not provide people with a controlled "opt-out" mechanism to exit the auction once they are engaged in the exercise. Pressing people to state a bid in an auction that they do not want to participate could serve to pressure the person, thereby violating his or her participation constraint. Bidders can opt-out of the experiment by bidding zero, as a result of this violation (see Cherry, Frykblom, Shogren, List, and Sullivan 2004 for an example and

\footnotetext{
${ }^{1}$ We wish to thank Romain Zeiliger and Maxim Frolov for their assistance in developing the software and Bruno Rock for his help in running the experiment. We gratefully acknowledge Russell Davidson, Edward Deci, Bernard Fortin, Alan Kirman, Danica Prelec, Drazen Prelec, Stéphane Robin, Laura Taylor, Miriam Teschl and participants in the ANR Workshop on incentives and motivation, 2008 (Paris); Tenth Annual CU Environmental and Resource Economics Workshop, 2008 (Vail) and seminars at University Paris 1 Panthéon-Sorbonne, GREQAM, Umea University, Columbia University, University of Colorado, University of Stockholm, University of Tennessee, Johns Hopkins University, University of NewCastle, University of Grenoble, University of Cambridge and MIT Sloan School of Management for comments on earlier versions of the paper. Two anonymous referees are also grateful for many insightful comments and suggestions for improvement. Support from the Paris School of Economics was greatly appreciated. Financial support from the Risk Foundation (Health, Risk and Insurance Chair, Allianz) and the Provence-Alpes-Côte-d'Azur Regional Council is gratefully acknowledged. Nicolas Jacquemet acknowledges the support of the Institut Universitaire de France.

${ }^{2}$ The concern over hypothetical bias comes from the large literature on valuation through stated preference surveys both in the field and in the lab - see, among others, Cherry, Frykblom, Shogren, List, and Sullivan (2004); Blumenschein, Blomquist, Johannesson, Horn, and Freeman (2008) for a summary. Based on 83 studies, Murphy, Allen, Stevens, and Weatherhead (2005) for instance found the ratio of hypothetical-real bids ranged from near unity to 25 for different deliverable goods like irradiated pork, watercolor paintings, and maps.
} 
Jacquemet, Joule, Luchini, and Shogren 2011 for an extensive discussion on this issue) $3^{3}$ Hypothetical bids without binding budget constraints or real economic commitments without binding participation constraints can both cause problems even if the institution is demand revealing. This suggests we need to find an ancillary mechanism that commits the bidder to bid sincerely when stating their preferences.

Faced with such revelation problems, real-world courts ask witnesses to take an oath "to tell the truth and nothing but the truth". Using the theory of commitment from social psychology Kiesler, 1971; Joule and Beauvois, 1998), we herein use a solemn oath as an ancillary truth-telling-commitment device, asking our bidders to swear on their honour to give honest answers prior to participating in an incentive compatible second-price auction. We examine whether this traditional real-world institution can induce subjects to reveal their preferences sincerely. Bidders are free to sign the oath or not, and participation and earnings are not conditional on signing the oath. Our experimental evidence comes from two experiments, designed jointly: an induced value (IV) second-price auction and a homegrown value (HG) second-price auction. The design and rules implemented in both are as identical as possible. This allows us to build on the results from the controlled IV auction to interpret bidding behavior for a non-market good (donate to adopt a dolphin) for which we do not know the homegrown demand curve. For each experiment, we run three main treatments: the baseline disconnects bidding decisions and subjects' payoffs from the experiment (the traditional hypothetical context); the real setting reintroduces monetary incentives; and the oath treatment gives the subjects the option of signing an oath to tell the truth before participating in the baseline.

For induced values, our results show oath improved demand revelation - people tended to bid sincerely after taking an oath for a hypothetical auction; they did not bid sincerely with monetary incentives or under a no-oath hypothetical scenario. For homegrown values, the oath elicited preferences that seemed to reduce violations both in the experimental budget constraint (only $18.9 \%$ of bids are above the disposable income earned in the experiment compared to $47.7 \%$ in the hypothetical-only auction) and in the participation constraint (only $1.1 \%$ zero bids compared to $26.7 \%$ in the real-only auction). Put together, those results unambiguously support having subjects sign an oath to tell the truth has a significant impact on bidding behavior. We moreover confirm the robustness of the results through training subjects with the elicitation mechanism before the actual procedure takes place. We rely on further companion treatments to assess the reasons why it happens. First, we explore whether the oath works by helping subject to tell the truth, or through a change in their willingness to do so, by adding an explicit exhortation to truthfully reveal preferences - a procedure known as cheap talk scripts since Cummings and Taylor (1999). Our results support the second interpretation - oath seems to make people more willing to tell the truth. We then turn to the behavioral motives underlying the observed change

\footnotetext{
${ }^{3}$ There are also concerns for real behavior in induced value settings. For instance, experimental evidence suggests bidders off the margin of the market clearing price - i.e. bidders whose private value for the good is at the bottom end of the distribution in the population of bidders - are less likely to bid sincerely in demand-revealing auctions (see e.g., Kagel, 1995). Here off-the-margin bidders tend to over-bid if they perceive their induced value is far removed from the potential market clearing price in a real auction (see for example, Knetsch, Tang, and Thaler, 2001, Shogren, Margolis, Koo, and List, 2001). We will come back to this issue later on when analysing the findings of our testbed treatments based on induced values.
} 
in behavior. We provide insight to help disentangle the two main candidate explanations: intrinsic preference to behave in accordance with past actions or aversion to guilt. In an HG setting, adding explicit warnings about the negative consequences associated with lying is neutral on the effect of the oath. This points to internal reasons underlying the effect of the oath, which favors the commitmentbased interpretation. Overall, our findings suggest the oath has potential to create the commitment needed to better link intentions and actions in demand revelation.

\section{The oath as a commitment device}

The social psychology theory of commitment tells us the risk of lying is diminished within an oathtaking context 4 This behavioral constraint arises because the act of taking an oath is understood as a strong commitment (see Joule and Beauvois, 1998, for an extended review) 5 Kiesler and Sakumura (1966) define commitment as a "binding of the individual to behavioral acts" (p.349). This commitment means that one's past actions affects actions to come. In the social psychology literature, commitment is a behavioral phenomenon: behavior itself causes behavior; a view that conflicts with the traditional economic view that attitudes and beliefs cause behavior (see in particular Beauvois and Joule, 1996 Joule, 1998, on the importance of behavior). The magnitude of the behavioral effects of committing oneself to a particular task depends on the degree of commitment, in which commitment is "a continuous variable rather than a dichotomous one" (see Kiesler, 1971, p.30).

Social psychologists use distinctive procedures to produce commitment from people. The "Foot-inthe-door" experiment is a classic example. This method first asks subjects to perform an initial request purposefully designed so nearly everyone will comply. Subjects are then asked to perform a second task which is thematically in line with the first. An archetypal example is the panhandler who first asks a passer-by if he knows what time it is, and then asks him if he has any spare change. The usual finding is that people are more likely to agree to given spare change if they have already agreed to give out the time "for free" (see Burger, 1999, for a review). In their seminal experiment on foot-in-the-door devices, Freedman and Fraser (1966a) telephoned housewives in Palo Alto, California. They asked them if they would be willing to answer a few questions about the kind of soaps they use. Two or three days later, the housewives were asked if they would allow five or six men to visit her home for two hours to classify their household products. In this foot-in-the-door situation, $52.8 \%$ of the housewives agreed the second request; whereas in the control group in which only the second request was made, $22.2 \%$ agreed.

\footnotetext{
${ }^{4}$ As far as we know, the only explicit occurrence of the oath in the literature in economics is Braham and Bolle (2006). In a game theoretical framework, the authors consider institutional signals, such as an oath, as signal simpliciters - an unmistakable cue that serves to communicate information which can incite action or influence the behavior of others. As noted by Schlesinger (2008), however, the solemn oath is a serious promise made with the full intention of being kept. Beyond its informational content, an oath is above all a personal commitment.

${ }^{5}$ In economics, the idea of commitment has first been used in the context of "commitment device" (Schelling, 1960, Elster, 1977) in economics at least since Schelling (1960) and Elster (1977). Their individual commitment devices that work to solve problems of self-control and inter-temporal inconsistencies (see Brocas, Carrillo, and Dewatripont, 2003, for a review). This literature, however, has not put forward any direct link with the social psychological theory of commitment.
} 
The "low-ball" technique is another method known to produce commitment from people. Low-balling works as follows: a monitor first secures the consent of a person asked to perform a target behavior before informing him or her of the full costs of the target behavior (or before increasing significantly the costs of the target behavior). Beauvois and Joule (and with colleagues) have applied this technique in numerous real-world applications; called "amorçage" in French, see Joule and Beauvois (1998) for a review of their findings. Although both the foot-in-the-door and the low-ball techniques rely on the person performing an initial request, the difference between the two is that in low-balling the preliminary request is the target behavior itself. In the first low-ball experiment Cialdini, Bassett, Miller, and Miller (1978) asked students to participate in an experiment taking place at the University at an unsocial time, i.e. 7:00AM 6 In the control condition, the students were told up-front about the timing of the experiment. In the low-ball condition, the experimenter first asked students to participate in an experiment without telling them the timing. Once the experimenter obtained a "yes" from a student, he would then tell him or her that the experiment would take place at 7:00AM. A volunteer could withdraw if he or she wished. They found that about half of students (56\%) in the low-ball condition made an appointment, whereas $31 \%$ did in the control condition. Among students who complied verbally with the request, $95 \%$ showed up at $7 \mathrm{am}$ in the low-ball condition; $79 \%$ did so in the control condition. Other studies have found that the low-ball strategy is more effective than the foot-in-the-door method; the explanation being that the preliminary request is the target behavior. Cialdini, Bassett, Miller, and Miller (1978) assert that the results of their studies indicate that "the low-ball phenomenon is reliable, robust, and mediated by a commitment to an initial, uncoerced decision to perform a behavior".

These two commitment techniques and others have been extensively discussed in the commitment literature (see for example Joule, 1998; Beauvois and Joule, 2002; Cialdini and Sagarin, 2005) 7 Each method shares a common and fundamental characteristic: commitment is created through a volitional action. The initial task and behavior is done freely by the subject; in practice, the instructions emphasize "freedom of choice" (see Kiesler, 1971; Joule, 1998). Guéguen, Joule, Halimi-Falkowicz, Pascual, FischerLokou, and Dufourcq-Brana (2011) show that fostering the feeling of freedom by a declaration of freedom during the initial request increases the degree of commitment. The rate of acceptance of the target request increases significantly and the effects of commitment last longer as compared to treatments in which no declaration of freedom was made at the initial request. The main reason behind such a strong influence of the freedom to choose lies in the way commitment "frames" people: if the commitment device is mandatory, it is perceived as complied with for external reasons by the subjects, and fails to change

\footnotetext{
${ }^{6}$ Low-balling or "throwing a low-ball" was already known in some sales organizations, in particular among new-car dealers. It consisted of selling a car at a good price and to remove the price advantage once the customer agreed, by selling for instance a very expensive option (Cialdini, Bassett, Miller, and Miller, 1978).

${ }^{7}$ The "four wall" and "lure" methods are variations that also have been shown to produce commitment from people. First suggested by Cialdini and Sagarin (2005), the four wall method asks four questions to which the person is likely to say "yes". Using this variant of the "foot-in-the-door", Guéguen, Marchand, Halimi-Falkowicz, and Joule (2011) show that this four wall technique is an effective tool to produce commitment. The "lure" technique is a variant of low-balling. A monitor obtains the consent of the person before telling him or her that the action she agreed to do is not available anymore but an alternative, less advantageous for the person, is now available.
} 
subsequent behavior 8 In addition, non-voluntary oaths may create its own psychological problems - we might induce reactance by making the oath mandatory (Brehm, 1966).

In addition, experiments in social psychology have shown people who initially commit to an action via a promise are more likely to follow through with the action. In Kulik and Carlino (1987), for instance, parents of a child suffering from an inner ear infection (otitis media) were asked to express a verbal promise to give their child all prescribed antibiotic medication. Parents who were committed through this verbal promise showed significantly higher compliance than a control group of parents who had not been asked to promise. Interestingly, recent findings from economic experiments support this form of commitment. In studies focusing on pre-play communication in games, people are observed to make promises to other players about what they are going to do later in the game. Moreover, those people who made promises in the communication phase are found to be likely to keep them when playing in both a hold-up game (Ellingsen and Johannesson, 2004) and in trust games (Charness and Dufwenberg, 2006).

Finally, experiments in social psychology have shown that commitment holds with even greater force when it has been written down and signed or publicly announced (Pallack, Cook, and Sullivan, 1980: Katzev and Wang, 1994). For instance, Wang and Katsev (1990) asked people to sign an agreement to recycle paper by throwing used paper in a specific container. This minor addition to the design increased the average weight of recycled paper by more than one hundred percent. Similar results were obtained by asking people to sign an agreement to replace ordinary lamp bulbs at home by low consumption ones (Joule, Girandola, and Bernard, 2007) or to shower instead of bath (Joule, Bernard, and HalimiFalkowicz, 2008). When commitment is made stronger through writing or public announcement, the change in behavior is longer-lasting, and survives after the promise have been made (Geller, Kalsher, Rudd, and Lehman, 1989, Boyce and Geller, 2000).9

To sum up, commitment theory states that commitment is stronger if it has been made freely, publicly expressed, or has consequences for the subject, or all three. Under these conditions, commitment induces strong and lasting changes in behavior. Using commitment theory as our guide, creating an oath that is publicly expressed, taken freely and signed, appears an extreme and more accentuated commitment device than a verbal promise or a written undertaking. Our working hypothesis is that an oath should help induce people to be consistent with their initial commitment in subsequent decisions 10 We apply this oath-as-commitment device to preference elicitation -we ask people to commit to tell the truth prior

\footnotetext{
${ }^{8}$ For example, Pratkanis (2007) lists 107 techniques of social influence. All share a common feature: no external factors are used. Subjects are free to comply.

${ }^{9}$ The precise design we chose for the oath is a private administration by one monitor. As compared to other options, such as a public administration of a personal oath, or a collective oath, private administration seems more effective and cause less uncontrolled outcomes than public and collective administration of the oath, which are subject to group effects and social pressure issues that have been raised in other work - e.g. Andreoni and Bernheim (2009).

${ }^{10}$ One might ask whether the oath as a commitment device is not just a form of "priming" - the use of a stimulus, without the subject noticing it, "to sensitize the nervous system to a later presentation of the same or a similar stimulus" Kolb and Whishaw 2009, p. 494). In a typical priming experiment, the person is for example primed through a list of words that is handed out to her. She is then presented with stems of 3 letters and asked to complete them to form a word that first comes to their mind (word-stem completion task). Empirical evidence shows that primed people are more likely to
} 
Table 1: Experimental design

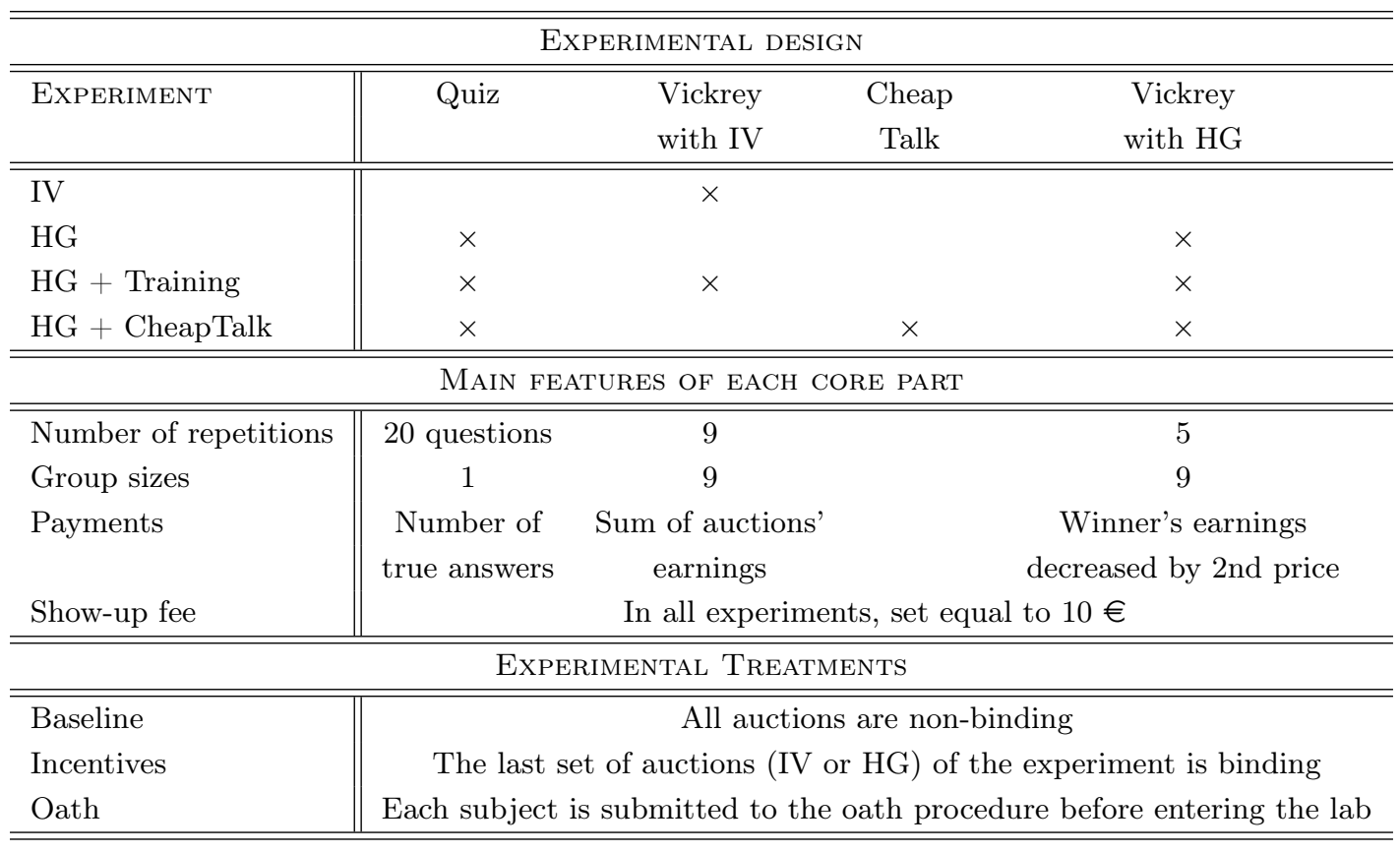

to stating their preferences for auctioned goods. We now discuss our general experimental design with the oath procedure.

\section{Overview of the experimental design}

The open question this paper addresses is whether an oath can induce more sincere bidding behavior, thanks to commitment, thereby improving the power of demand revelation and the accuracy of stated preference methods. We test whether a person taking an oath bids more sincerely in an incentivecompatible auction, both in induced and homegrown value auctions. Table 1 provides an overview of the experimental design) Throughout the paper, we hold constant the demand revelation mechanism - the

complete stems with the words that were presented to them in the list than with a new word. Another example deals also with lists of words. Subjects have to memorize words with a positive tone (like self-confident, adventurous, etc.) or with a negative tone (pretentious, unthoughtful, etc.). Later, subjects are presented with the story of a person who has been for instance windsurfing across the Atlantic. When asked what they think about this person, subjects who have been primed with negative connotation words tend to give negative value judgments and conversely for subjects being primed with positive connotation words (see for instance Higgins, Rhodes, and Jones, 1977). The key feature of priming experiments is that subjects are not aware of being primed, i.e. priming is an implicit memory effect. In this respect, it can be said that an oath is a primer that reminds the person to tell the truth. Oath as-commitment-device involves more than priming. First, the oath explicitly mentions to "tell the truth" whereas a prime is implicit by definition. Second, the person is free to sign an oath. That is, the person is free to choose to "prime herself". Priming, as we have seen, happens without the person's awareness and direct consent. Finally, commitment concentrates on the accomplishment of a behavior, and not on a particular cognitive feature only. 
classic second price Vickrey auction. We purposefully chose to test the oath by working with the Vickrey auction rather than a discrete choice elicitation mechanism because the auction has three attractive features for our testbed purpose. First, Vickrey auctions are weakly demand-revealing with monetary incentives: in theory, each bidder's weakly dominant strategy is to bid her or his induced value (Vickrey, 1961). Second, market price is endogenous rather than arbitrarily chosen by the experimenter. Third, bidders announce their value for the good in a continuous manner. It provides continuous observations on individual preferences - as compared to only mass points with provision point mechanisms - and allows for much more precision in the statistical analysis. Future work can explore how the oath operates in alternative discrete choice preference elicitation mechanisms, e.g., referenda voting, provision point. Note however that all results are derived from differences in elicited demand - holding the mechanism constant. This would undermine any effect due to the specificity of the mechanism itself.

We start by testing the oath both with and without monetary incentives in an IV auction, that provides the highest level of control on preferences (Section 4). In our treatments, truth-telling is the relevant comparative benchmark, not "real bidding behavior", which we know from evidence and experience has been unreliable in the second-price auction. We want to know precisely this: "whether an oath makes players more likely to bid their induced value". Given past experimental evidence revealing suboptimal bidding in the auction without the oath, reasons exist to question both hypothetical bids and monetary incentives bids. We want to explore whether the oath works to induce equilibrium behavior in this setting - which is to tell-the-truth. These different treatments allow us to calibrate observed bidding behavior against theory and against each treatment. We then move to settings closer to the field. First, we examine how the oath affects preference elicitation of $\mathrm{HG}$ values to protect dolphins compared to hypothetical and real bidding (Section 5). Second, the robustness of those results are assessed through additional treatments in which we rely on the IV auction design to train subjects with the mechanism before entering the dolphin adoption auctions (Section 6). We conclude the paper with further treatments aimed at exploring how and why the oath works. Our first concern is to contrast the performance of the oath with explicit exhortations to tell the truth. This led us to design treatments that implement so-called cheap talk scripts, that inform subjects about hypothetical bias and its unwarranted consequences (Section 7). Last, we examine the behavioral motivations underlying this effect from alternative combinations of our experiment treatments (Section 8 )

\section{Testbed treatments: The oath in an IV auction}

\subsection{Design of the IV-Experiment}

Our first experiment implements a three-treatment design of an IV auction: (i) baseline hypothetical bidding, with neither an oath nor monetary incentives; (ii) baseline coupled with an oath and (iii) bidding with binding monetary incentives. 
IV-Baseline. We use a Vickrey second price auction, in which the highest bidder pays the secondhighest bid. We divide each 18-subjects session into two independent groups of nine bidders to avoid too much distortion of bidding at the bottom of the distribution of bids (see Kagel, 1995). In each auction, each bidder is endowed with a single induced value - i.e., the price at which the bidder can sell the good to the monitor after the auction.

The induced demand curve is identical in all auctions and we hold constant the points at which we elicit preferences, to avoid unwarranted noise between rounds. The demand curve in each auction is defined by: $\{84 ; 76 ; 71 ; 68 ; 65 ; 63 ; 53 ; 38 ; 24\}$. All monetary values are expressed in ECU (Experimental Currency Unit). The auction is repeated over nine rounds, implementing all possible permutations among individual private values: each bidder experiences each private value once, and the entire demand curve is induced in every period. At the end of the sequence of bids, the results from each auction round are displayed to the subjects. Bidders receive no information about the bids of others until the end of the auction. Hypothetical profits equal the difference between the induced value and the price the winning bidder pays for the good (the second highest bid). If a bidder does not purchase the good, her profit is zero for that round. Only the winner sees the two highest bids at the end of the round.

Although the repetition is deterministic, we avoid end-game effects by providing the subjects with no information on that point - except for the repetition itself. Each bidder knows nothing about the other bidders' induced value or the induced demand curve. A bidding period ends when each bidder has chosen a bid between 0 and 100. After each round, bidders are informed on their screen about whether they won and, in this case only, the market clearing price and the hypothetical earnings for that period. Lastly, everybody is informed about whether a new auction period is about to start. Each bidder is paid a flat $10 €$ show-up fee for participating in the experiment.

IV-Incentives. This treatment makes bidding behavior binding - auction winners earn their takehome pay based on the accumulated difference between their induced value and the market-clearing price for each round in which they win the auction. The common knowledge exchange rate is 3ECU for $1 €$. The monetary values in ECU accumulated across all auction periods are added to a $10 €$ show-up fee - in the event of negative total earnings, the show-up fee could decrease to as low as $5 € 11$ The monetary incentives are common knowledge, since we state explicitly that payments depend upon decisions made in each period at the beginning of the written instructions, and repeat this at the end.

IV-Oath. This treatment is identical to the baseline except each subject is asked to sign an explicit oath before entering the lab. The oath is implemented as follows: each subject enters alone and is directed to a monitor at the front of the laboratory. The monitor then offers each subject a form to sign entitled "solemn oath" (see Figure 1) 12 The Paris School of Economics logo on the top of the form and the address at the bottom indicate that it is an official paper; the topic designation and the

\footnotetext{
${ }^{11}$ We contractually commit ourselves to a minimum earning of $5 €$ when recruiting participants.

${ }^{12}$ The "Oath" is written on the form and read by the subject, but never said aloud.
} 
Figure 1: Oath form used in the experiments

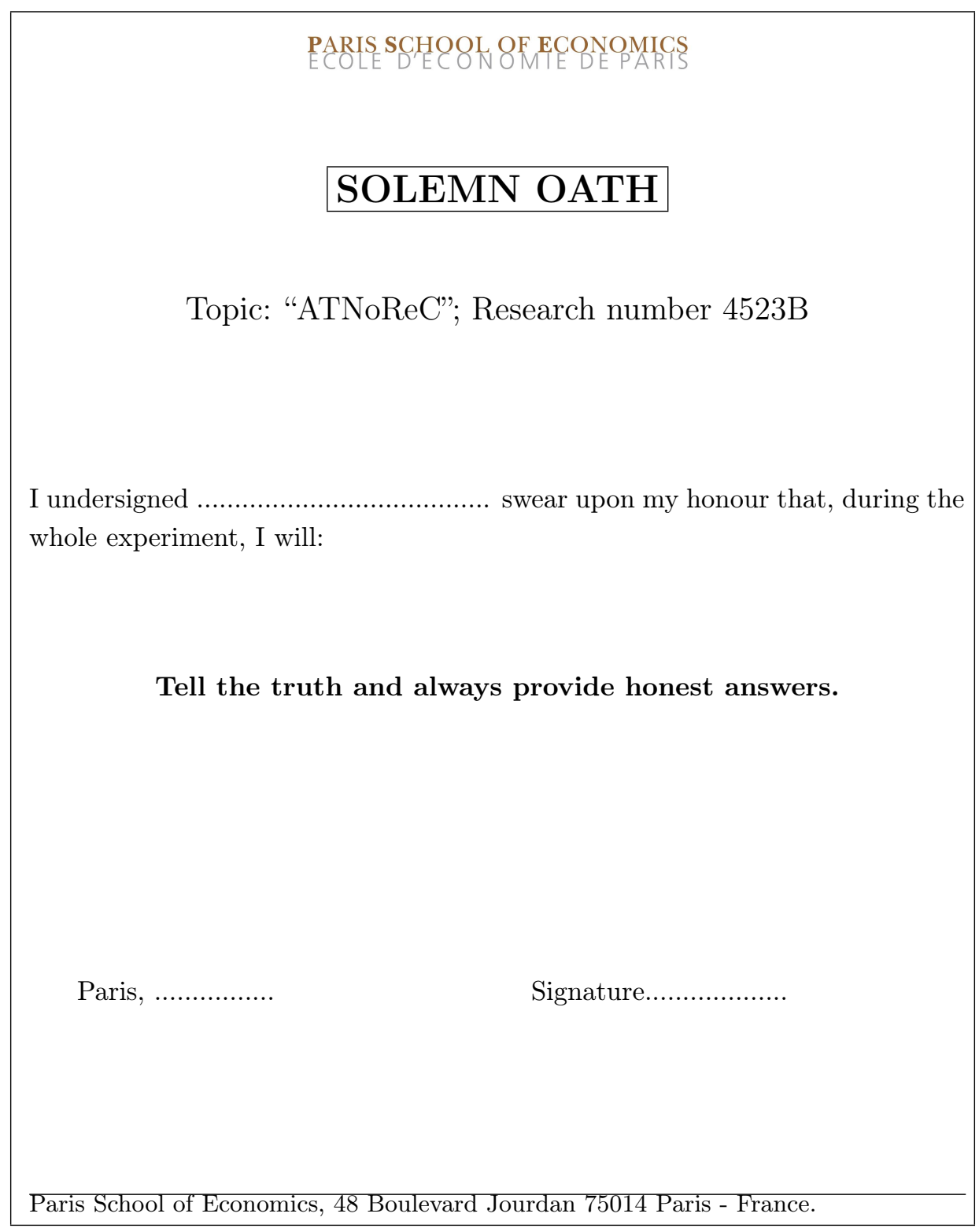

research number were added so to ensure the credibility. The monitor explicitly points out to the subject before he or she reads the form that he or she is free to sign the oath or not, and that participation and earnings are not conditional on signing the oath (subjects are, however, not informed about the topic of the experiment when asked to take the oath). The subject reads the form, which asks whether he or she agrees "to swear upon my honour that, during the whole experiment, I will tell the truth and always provide honest answers" (emphasized in the original form). We chose the wording "solemn oath" and "upon honour" given the secularism of French modern society, in which law and political parties cannot 
be based on any religion 13 Regardless of whether the subject signs the oath, he or she is thanked and invited to enter the lab. The exact wording used by the monitors to offer the oath to respondents was scripted to standardize the phrasing of the oath. One monitor stayed in the lab until all subjects had been presented with the oath, to avoid communication prior to the experiment. Subjects waiting their turn could neither see nor hear what was happening at the oath-desk.

\section{$4.2 \quad$ Experimental procedures}

Three experimental sessions - one per treatment - were conducted at University Paris I. Each session involved 18 subjects, providing two independent nine-times repeated Vickrey auctions 14 On arrival, a monitor welcomes the participants and distributes an individual consent form. Unlike the oath form, the consent form is mandatory and publicly distributed. It also indicates that the subject will earn at least $5 €$ in the experiment. Participants hand in the form to the monitor before entering the lab. In the IV-oath treatment, the consent form is picked up at the private desk, before the oath presentation. A computer is then randomly assigned to each subject and a monitor distributes and reads aloud the instructions 15 To improve understanding of the game, a non-numerical example is developed covering all the instructions. However, the instructions do not indicate that bidding one's induced value is the dominant strategy. Participants are also asked to answer a short questionnaire highlighting the most salient features of the game. Once the questionnaire is orally corrected the experiment begins.

In each session, subjects begin by answering a short socio-demographic survey about individual characteristics (gender, age, ...). The auction rounds then start. After nine rounds, the monitor pays each subject privately in cash - a fee of $10 €$ in the baseline and oath treatments and a sum computed from this same fee and the amount of ECU accumulated (or lost) in the monetary incentive treatments. Overall, 72 subjects participated, yielding 162 bid observations for each treatment. The experiment lasted around half an hour and the average take-home earnings was about $10 €$.

\section{$4.3 \quad$ Results}

Table 2 provides raw data on observed behavior by treatment and round. Given the constant demand curve induced in each round, the induced aggregate demand is always the same, equal to 1084. For each treatment, the first row of the table gives the aggregate demand we actually observe and the second row provides the ratio between the two - a score of 100 indicating perfect revelation of the demand induced in the auction. Contrary to most studies run in North America (see Murphy, Allen, Stevens, and Weatherhead, 2005, for a survey) we do not observe a bias between the IV-Baseline and IV-Incentives

\footnotetext{
${ }^{13}$ The French Constitution is itself based on such an oath: the Tennis Court Oath (in French, serment du Jeu de Paume) which was an oath signed by the members of France's Third Estate to continue to meet until a constitution had been written, despite royal prohibition.

${ }^{14}$ All experiments were computerized using a software program developed under REGATE (Zeiliger, 2000) and participants were recruited based on ORsEe (Greiner 2004).

${ }^{15}$ An english translation of the original instructions in French is available from the authors upon request.
} 
Table 2: Induced value bidding behavior by group and round

\begin{tabular}{lcccccccccc}
\hline \hline $\begin{array}{c}\text { Aggregate Demand } \\
\text { 1084 }\end{array}$ & \multicolumn{1}{c}{ Round } & & & & \\
& 1 & 2 & 3 & 4 & 5 & 6 & 7 & 8 & 9 & Total \\
\hline \hline \multirow{2}{*}{ IV-Baseline } & 938 & 992 & 1140 & 1103 & 1221 & 1153 & 1179 & 1142 & 1266 & 10134 \\
& 86.5 & 91.5 & 105.2 & 101.8 & 112.6 & 106.4 & 108.8 & 105.4 & 116.8 & 103.9 \\
\hline \multirow{2}{*}{ IV-Incentives } & 949 & 1081 & 1245 & 1149 & 1062 & 1254 & 1290 & 1168 & 1130 & 10328 \\
& 87.5 & 99.7 & 114.8 & 105.9 & 98.0 & 115.7 & 119.0 & 107.7 & 104.2 & 105.9 \\
\hline \hline \multirow{2}{*}{ IV-Oath } & 977 & 1121 & 1117 & 1093 & 1214 & 1172 & 1155 & 1093 & 1186 & 10128 \\
& 90.1 & 103.4 & 103.0 & 100.8 & 112.0 & 108.1 & 106.5 & 100.8 & 109.4 & 103.8 \\
\hline \hline
\end{tabular}

Note. The aggregate induced demand (sum of the induced values exogenously attributed to the buyers) is the same in each round, equal to 1084. For each treatment in row, the upper figure gives the aggregate revealed demand (observed bids) in each round (in column) and summed over rounds (last column). The lower figure gives the ratio of this revealed demand to the aggregate induced demand, in \%.

treatments. After nine rounds, we elicit $103.9 \%$ of the total induced demand in the baseline and $105.9 \%$ in IV-Incentives. This feature has been replicated in valuation experiments in France (see e.g., Ehmke, Lusk, and List, 2008; Jacquemet, Joule, Luchini, and Shogren, 2011).

Result 1 All three treatments perform equally well in terms of aggregate demand revelation.

Support. We compare treatment mean bids by performing non-parametric bootstrap mean difference tests that account for potential correlation between the 9 bids of the same subject. The procedure consists of bootstrapping subjects and their corresponding bids instead of bootstrapping on bids. A first bootstrap test indicates that mean bid in IV-Baseline and mean bid in IV-Incentives are not statistically different $(p=.679)$. This is also the case when mean bid in IV-oath is compared to IV-Baseline $(p=.618)$ and to IV-Incentives $(p=.999)$.

But this does not imply that our bidders perfectly revealed their true value for the good. Past experimental evidence has shown that the second-price auction with monetary incentives only leads to mixed performance at the individual level - as bidders overbid or underbid relative to their induced value (see Kagel, 1995). This is particularly salient for off-the-margin bidders, i.e., bidders whose private value for the good is at the lower end of the distribution (Parkhurst, Shogren, and Dickinson, 2004).

In line with this, we observe poor revelation of the whole demand curve for both treatments. Table 3 organizes the data by induced values. For each induced value, the aggregate demand is 18 times the individual value (nine bidding rounds times two auctions in each treatment) and the bottom part of the top row of the table provides the resulting aggregate demand. For each treatment, we report the revealed aggregate demand and the ratio between induced and revealed demand. Note, each cell in this table comes from bidding in all nine rounds, since each value is induced once and only once in each round for each market. Demand revelation almost monotonically decreases, from $159 \%$ under binding incentives 
Table 3: Induced value bidding behavior by group and Induced Value

\begin{tabular}{lcccccccccc}
\hline \hline \multirow{2}{*}{$\begin{array}{l}\text { Induced value } \\
\text { Aggregate demand }\end{array}$} & 24 & 38 & 53 & 63 & 65 & 68 & 71 & 76 & 84 & Total \\
& 432 & 684 & 954 & 1134 & 1170 & 1224 & 1278 & 1368 & 1512 & 9756 \\
\hline \hline \multirow{2}{*}{ IV-Baseline } & 626 & 808 & 1050 & 1193 & 1201 & 1192 & 1242 & 1290 & 1532 & 10134 \\
& 144.9 & 118.1 & 110.1 & 105.2 & 102.6 & 97.4 & 97.2 & 94.3 & 101.3 & 103.9 \\
\hline \multirow{2}{*}{ IV-Incentives } & 687 & 735 & 1078 & 1045 & 1318 & 1259 & 1281 & 1334 & 1591 & 10328 \\
& 159.0 & 107.5 & 113.0 & 92.2 & 112.6 & 102.9 & 100.2 & 97.5 & 105.2 & 105.9 \\
\hline \hline \multirow{2}{*}{ IV-Oath } & 475 & 757 & 1046 & 1129 & 1261 & 1249 & 1331 & 1345 & 1535 & 10128 \\
& 109.9 & 110.7 & 109.6 & 99.6 & 107.8 & 102.0 & 104.1 & 98.3 & 101.5 & 103.8 \\
\hline \hline
\end{tabular}

Note. The first row reports the induced values (IV) attributed to buyers. The second row reports the corresponding aggregate demand $(\mathrm{AD})$ in each treatment, i.e., induced values $\times$ number of subjects. For each treatment (four remaining rows), the upper part of the row displays the revealed aggregate demand (RAD), i.e., the observed bids posted by buyers the induced value of whom are reported in column. The lower part reports the ratio of this revealed demand to the aggregate induced demand, in $\%$.

- and $145 \%$ in IV-Baseline - for the lowest induced value, to rather satisfactory revelation (105\% under monetary incentives and $101 \%$ in the baseline) for the highest induced value. If all subjects maximized their personal payoff, each bid should equal the induced value. In our setting, $5.5 \%$ of bids are perfectly demand-revealing in the IV-Baseline treatment; $19.1 \%$ of bids were within a \pm 2 percent interval centered on the induced value. With monetary incentives, $12.3 \%$ of bids equal the induced value and $15.4 \%$ were within a \pm 2 percent interval. According to a non-parametric bootstrap proportion test that account for correlation across the nine bids of the same subject, the increase in bids equals to induced value in IV-Incentives is significant when compared to the proportion of bids equal to the induced value in IVBaseline $(p=.036)$ whereas the difference is not significant when looking at the proportion of bids within a $2 \%$ range of the induced value $(p=.382)$. In IV-Baseline, eight subjects out of 18 bid their induced value at least once during the whole experiment while 11 do so in IV-Incentives. Seven subjects do it at least twice and only two do it three times in IV-Baseline. With monetary incentives, five subjects bid at least twice their induced value and four subjects at least three times. When looking at subjects who bid within the $2 \%$ range of the induced value, we find that 13 subjects do so at least once in IV-baseline and 14 in IV-Incentives. Ten subjects out of 18 bid within the $2 \%$ range at least twice in IV-Baseline and eight in IV-Incentives. Five of the 18 subjects bid within the $2 \%$ range at least three times in IV-Baseline and three with monetary incentives. In both treatments, none of the subjects bid in the $2 \%$ range of the induced value in all nine auctions. The highest number of times a subject bid in the $2 \%$ range of the induced value is three for three subjects in IV-Baseline and four for three subjects in IV-Incentives. Insincere bidders both inflated and shaved bids in near-equal percentages: $46.3 \%$ and $48.1 \%$.

Result 2 In an induced value second price auction, bidding behavior both with and without monetary incentives differs from perfect demand revelation.

Support. We first test the assumption of perfect revealing bid at the aggregate level by examining bidding behavior of off-the-margin bidders. We do so by testing the bid to induced value ratio. If the 
bidder bids his or her induced value, i.e. tells the truth, the ratio equals one. Bootstrap tests reject the null of perfect demand-revealing bids for the lowest induced value (24 ECU) with $p$-values 0.016 in IV-Baseline and 0.018 in IV-Incentives.

We test the assumption of perfect revealing bids all along the demand curve by specifying the true underlying bidding function as linear in induced value: $b_{i t}^{*}=\beta \nu_{i t}+\alpha+\phi_{t}+\alpha_{i}+\epsilon_{i t}$, where $b_{i t}$ denotes subject $i$ 's ECU bid in trial $t ; \nu_{i t}$ denotes subject i's induced value in trial $t ; \phi_{t}$ are fixed-round effects and the $\alpha_{i}$ 's are zero mean subject-specific random variables with common variance $\sigma_{\alpha}^{2}$. This last term accounts for individual heterogeneity in bidding behavior. The bids we observe, $b_{i t}$, are censored at 0 and 100 due to the design of the experimental auction. We estimate the true underlying parameters by fitting the latent variable model: $b_{i t}=\min \left[\max \left(b_{i t}^{*}, 0\right), 100\right]$. Assuming normality of the idiosyncratic error term, this defines a panel Tobit model censored at both 0 and 100.

The model is implemented by assuming that the distribution of heterogeneity in the population, $\alpha_{i}$, is normal and uncorrelated with the idiosyncratic error. Econometric results are given in Table 4. Based on the estimated parameters of the bidding function, we can test for perfect revealing bids for each treatment by considering $H_{0}:\left\{\beta=1, \alpha=0, \phi_{t}=0 \forall t\right\}$. Results from Wald tests for the first two treatments are:

$$
\begin{array}{llllll}
\text { IV-Baseline } & : & W=38.66 & p=0.0000 & H_{0} & \text { Rejected } \\
\text { IV-Incentives } & : & W=23.36 & p=0.0095 & H_{0} & \text { Rejected }
\end{array}
$$

We reject the perfect revealing bids for both treatments 16

This leaves the door open for improvement, and we now look at whether we can make sincere bidding more likely by asking bidders to freely take a truth-telling oath prior to participating in the baseline auction. Nearly all subjects had no problems with taking the oath; they chose to do so quickly. Some even pointed out that responding truthfully during the experiment was natural and entirely normal as shown above, however, telling the truth is not obvious at all in neither IV-Baseline nor IV-Incentives treatments. The acceptance rate is $94.5 \%$ since only one subject out of eighteen refused to take the oath. Self-selection is not an issue 17

The third line of Table 2 describes bidding behavior in the IV-Oath treatment by round. Looking at the first round, which is a useful exercise to understand initial reactions to the auction under oath, we do not observe a clear difference between treatments. Aggregate Elicitated demand under oath in the first round is closer to aggregate induced demand than elicited demand in IV-baseline and IV-incentives but not by much.. The third line of Table 3 describes bidding behavior in the IV-Oath treatment by induced value. Aggregate bidding behavior exhibits satisfactory revelation over the whole demand curve. In particular, we do not observe over-bidding for the lowest induced value: the ratio of revealed aggregate demand over induced aggregate demand is $110 \%$. In addition, $16.0 \%$ of bids equal the induced value and $35.8 \%$ are within a 2 percent interval centered on this value. According to a non-parametric

\footnotetext{
${ }^{16}$ Note that this result still holds for both treatments when the lowest bid is removed: $p=.072$ for IV-Baseline and $p<.001$ for IV-Incentives.

${ }^{17}$ Five percent refusal rate is standard for commitment experiments (Joule and Beauvois, 1998, Burger, 1999).
} 
Table 4: IV bidding behavior - Panel Tobit estimations

\begin{tabular}{lccc}
\hline \hline Variable & IV-Incentives & IV-Baseline & IV-Oath \\
& $n=162$ & $n=162$ & $n=162$ \\
\cline { 2 - 4 } & \multicolumn{3}{c}{ Parameter estimates } \\
& \multicolumn{3}{c}{$(p$-value $)$} \\
\hline \hline$\nu_{i t}$ & 0.855 & 0.788 & 0.969 \\
& $(0.000)$ & $(0.000)$ & $(0.000)$ \\
Constant & 0.48 & 4.44 & -6.10 \\
& $(0.945)$ & $(0.394)$ & $(0.182)$ \\
Round dummies & YES & YES & YES \\
\hline \hline \multirow{2}{*}{$\sigma_{u}$} & 2.40 & 9.19 & 8.72 \\
& $(0.000)$ & $(0.000)$ & $(0.000)$ \\
$\sigma_{\epsilon}$ & 19.55 & 14.25 & 12.64 \\
& $(0.000)$ & $(0.000)$ & $(0.000)$ \\
\hline \hline Log-likelihood & -675.11597 & -659.40375 & -641.81659 \\
\hline \hline
\end{tabular}

Note. Individual random effects Tobit models. The random effects are assumed normal; round (fixed) effects are controlled for in the estimation, but omitted in the Table. The endogenous variable is the bid posted. $\nu_{i}$ denotes the induced private value.

bootstrap proportion test, this proportion is significantly higher than in IV-Baseline $(p=.051)$. It is not significantly higher when compared with IV-incentives $(p=.473)$. The proportion of bids within a \pm 2 percent interval centered on the induced value is $35.8 \%$. The increase is statistically significant when compared to IV-Baseline $(p=.016)$ and to IV-Incentives $(p=.057)$. When under oath, 11 subjects out of 18 bid at least once their induced value. Five of the subjects under oath do so twice and four do it at least three times in the nine auction rounds. We find that 15 subjects bid at least once in the $2 \%$ range of their induced value when under oath; 11 subjects do it at least twice and nine subjects at least three times. One subject bid nine times in the $2 \%$ range; one eight times; two seven times; and one six times. Insincere bidders tend to inflate rather than shave their bids: $50.7 \%$ of bids were higher than the private value and $33.3 \%$ lower.

Result 3 In a hypothetical second price auction, asking a bidder to take an explicit oath pledging to tell the truth and always provide honest answers leads to sincere bidding behavior.

Support. We first consider off-the-margin bidders behavior by testing the equality to one of bid to induced value ratio. A bootstrap test cannot reject the null of perfect-demand revealing behavior for the lowest induced value: $p=0.340$. Based on the Tobit regression provided in Table 4 , we examine individual bidding behavior all along the demand curve by applying the Wald test of perfectly revealing bids to the IV-oath treatment.

$$
\text { IV-Oath } \quad: \quad W=15.55 \quad p=0.1133 \quad H_{0} \quad \text { Not rejected }
$$


We cannot reject the null hypothesis that the subjects motivated by the oath bid sincerely. We used the treatment variable - each subject was asked to take an oath, and not whether or not he or she agreed to take the oath. Descriptive statistics and econometric tests lead to similar conclusions when the subject who did not sign the oath is dropped from the analysis ${ }^{18}$

To sum up, the oath procedure significantly improves the power of the Vickrey mechanism to reveal true values for the good. The IV context leads to revealed preferences which are overall quite close to the induced ones. The effect of the oath on the truthfulness along the whole demand curve is thus rather thin. A notable effect of the oath, however, is to discipline the bidding behavior of off-the margin bidders, who drive the rejection of perfect revelation in all other contexts. IV auctions provide persuasive results on the performance of our elicitation procedures, because preferences are perfectly observed and controlled. The second set of experiments applies the same experimental design to a setting closer to the field as regards the good sold in the auction.

\section{Application treatment: The oath in HG auctions}

We now consider preference elicitation of homegrown values for a private good with non-market attributes: adopting a dolphin through a monetary donation to the World Wide Fund (hereafter WWF), a well-known non-governmental organization devoted to "protecting the future of nature" 19 Subjects' homegrown values are elicited using the same elicitation mechanism, a second-price auction. The price for improved parallelism with decisions in the real world is the lack of control over true preferences in this experimental setting. We focus on three treatments: hypothetical bids (HG-Baseline), bids with binding monetary incentives (HG-Incentives), and an oath prior to hypothetical bidding (HG-Oath).

\subsection{Design of the HG-experiment}

The good. We focus on preferences for the "private adoption" of a wild dolphin, a private good with potential public good spillovers (only the winner gets the official adoption certificate and a photo of the adopted animal). The WWF offers people the opportunity to "adopt" an endangered animal species. This adoption takes the form of an individual donation to a program aimed at fighting threats like habitat loss and poaching faced by endangered animals. Depending on the amount of the donation (among three possible values), donators are sent private gifts such as an adoption certificate, a photograph of the animal, a cuddly stuffed toy dolphin, a gift box, and so on. For the purpose of our experiment, this procedure has the attractive feature of ensuring the credibility of the donation, thanks both to the WWF label and to the documentation associated with donation. We chose the entry-level offer, i.e., an

\footnotetext{
${ }^{18}$ Detailed results are available upon request from the authors.

${ }^{19}$ The WWF was formerly named the World Wildlife Fund, which remains its official name in the United States and Canada. Since 2001, the WWF has been named the World Wide Fund in all other countries. More information about the WWF can be found at http://www.worldwildlife.org/about/.
} 
adoption certificate and photograph are sent for each 25 USD (18.50 Euros when the experiments took place) donation to the WWF. Since the photograph and the adoption certificate are essentially symbolic in nature, this reduces the risk of valuations being influenced by "by-product" goods, such as a cuddly stuffed toy or a gift box.

The adoption procedure is described to the subjects using a French-language, slightly modified version of the official web page set up by the WWF ${ }^{20}$ The page provides a short description of a dolphin's life and of the WWF and, more importantly, a detailed presentation of the donation program and the documentation (gifts) sent should a subject adopt a dolphin. The scroll bar used to choose a donation amount between 0 and 30 Euros, along with an "OK" button, appears directly on the page and the subjects see the good description until they confirm their choice. The upper bound of 30 euros is the same for all subjects and does not depend on experimental earnings. As a result, subjects can bid above their experimental earnings and instructions clearly state that any bid above experimental earnings would have to be completed by out-of-pocket money. Neither do we impose a lower bound or reservation price in the provision rule - minimum bid is zero. The good sold in the experiment is potentially cheaper in the lab than in the market, so we subsidize the winning donation to reach the market price when monetary incentives are binding. Subjects are not told anything about this subsidy. This is enough to protect our data from the censoring issue raised by, e.g, Cherry, Frykblom, Shogren, List, and Sullivan (2004), if all actual offers are below the market price (which is far from being the case in the experiment, see Section 5.3 below). In theory, this remains valid for every observed offer as long as subjects are not aware of the donation procedure and the market price of the donation outside the laboratory. To confirm that the observed values are independent of field opportunities, some items assessing subjects' knowledge about the procedure are included in a debriefing questionnaire (see Section 5.2 below).

Elicitation mechanism. As in the IV-Experiment, individual valuations for the good are elicited thanks to a Vickrey auction: each bidder privately posts a bid, the highest bid determines the winner of the auction, and the market price is the second highest bid. We reduced the noise in elicited preferences by repeating five times the auction. At the end of the sequence, one auction round out of the five is randomly drawn. The winner of the randomly drawn auction is the subject entitled to adopt a dolphin, and the amount of donation is equal to the market price for this round. For comparison purpose, we also divide each 18-subject session into smaller groups of 9 independent bidders: two groups in each session are involved in two independent adoption processes.

Show-up fee property rights. Our focus on donation behavior requires that subjects spend some money in the experiment. To improve the external validity of our design - in particular, to avoid an inflation in the number of false zeros - we want the subjects to enter the auctions with some positive experimental earnings to be spent on the donation. This would mean giving subjects a large show-up fee for participating in the experiment. Evidence suggests behavior can differ depending on whether

\footnotetext{
${ }^{20}$ The original page in English is available at https://secure.worldwildlife.org/ogc/ogcAC_speciesDetail.cfm? $\operatorname{gid}=8$.
} 
wealth is "windfall" or is earned (also called endowment effect, see, among others, Cherry, Frykblom, and Shogren, 2002). In the context of demand revelation using Vickrey auctions, Jacquemet, Joule, Luchini, and Shogren (2009) show that earned money makes a significant difference to bidding behavior as compared to windfall wealth. In line with these results, and to be as close as possible to actual stated preferences surveys in the field, we use an earned-wealth design. This also replicates a common feature of homegrown valuation experiments focusing on hypothetical bias (e.g., Cummings and Taylor, 1999. Cummings, Elliott, Harrison, and Murphy, 1997).

Earned wealth is implemented through a preliminary stage during which the subjects are asked to answer 20 general knowledge questions. Accompanying each question is a list of four possible answers. The set of questions was taken from the annals of the "Concours de Catégorie B de la fonction publique" which is a civil service entry test for those who hold at least the French baccalaureate21 This is appropriate to discriminate between undergraduate students. Accompanying each question is a list of four possible answers. Subjects are explicitly told that one and one only out of the four is true, and that monetary earnings labeled in ECU (Experimental Currency Unit) are proportional to correct answers. The position of the correct answer is randomized between questions and the ordering of questions is kept the same for all subjects in all treatments ${ }^{22}$

Experimental treatments. As in the IV experiment, we rely on three elicitation contexts: HGBaseline, HG-Incentives and HG-Oath. The first two treatments only differ regarding the monetary consequences of the adoption auction. The adoption is hypothetical in the HG-Baseline treatment while the donations are subtracted from subjects' earnings in the HG-Incentives treatment. This implies that donation is merely declarative in HG-Baseline and no funds are actually transferred to the WWF - no adoption certificate is sent to the adopter. All other experimental features are kept the same in these two treatments. The HG-Oath treatment adds an oath procedure to the HG-Baseline treatment: before entering the lab, each subject is asked to sign a "solemn oath" to tell the truth. The entire oath procedure is identical to that implemented in the IV-oath treatment described in Section 4.1. Earnings stemming from the quiz are real in all treatments to avoid unwarranted wealth differences between our treatments.

\subsection{Experimental procedures}

Three 18-subjects sessions, one per treatment, were conducted in the LEEP laboratory in Paris. Since each subject posts five bids for adopting a dolphin, this provides 90 bid observations for each treatment. On arrival, each subject signs an individual consent form and enters the lab. This form is mandatory for participation in the experiment. In the HG-oath treatment only, subjects are then asked to take a truth-telling oath, following the same procedures as those implemented in the IV-Oath treatment.

\footnotetext{
${ }^{21}$ Our source is http://pagesperso-orange.fr/bac-es/qcm/annales_c02_r01.html.

${ }^{22}$ The data on observed answers are not commented on here; the full list of questions and data are available from the authors upon request.
} 
A computer is then randomly assigned to each subject and a monitor distributes and reads aloud the instructions.

The experiment begins by asking the subjects to fill out a computerized questionnaire about socioeconomic characteristics. The instructions of each part of the experiment are distributed and read aloud just before it starts and participants are encouraged to ask clarifying questions, privately answered by the monitor. All treatments start with the quiz (questions along with the four possible answers are displayed one after the other). Subjects are provided information on their score only at the end of the quiz along with their corresponding earnings in ECU. The payment rate is 2 ECU per correct answer and the exchange rate is the same as in the IV experiment, $3 \mathrm{ECU}$ for $1 €$. With an expectation of ten correct answers out of 20 , the average monetary earnings for the quiz would be $7 €$, (payment is rounded up to the next 50 cents), which makes $17 €$ in total once added to the $10 €$ show-up fee.

The last part of the experiment in all three treatments is the adoption auction. The instructions first detail the WWF, the adoption procedure, and how the collected funds will be used. This description of the good is the main difference between the instructions used in the HG auction and those we used for the IV auction. The wording of the auction, in particular, is identical, calling the bids "prices" and the amount of the donation "market price". Subjects are grouped into two nine-bidder auctions. We also use the same non-numerical example and same questionnaire to check subjects' understanding at the end of the instructions. Treatments are implemented by slightly modifying the wording of the instructions between HG-Incentives and HG-Baseline. We follow Cummings and Taylor (1999) in replacing the affirmative language used in real auctions ("you will participate in the adoption procedure", "you will adopt a dolphin", "we commit ourselves to sending your donation to the WWF") with a subjunctive language in the hypothetical auctions: "we want you to suppose you were to participate in the adoption procedure", "you would adopt a dolphin", "we would commit ourselves to sending your donation to the WWF" (italics added).

At the end of the experiment, subjects are asked to answer a computerized debriefing questionnaire. The aim of the questions is to assess the level of knowledge and the level of agreement of the subjects as regards the WWF and its actions, their knowledge of the WWF adoption procedure, their degree of familiarity with the auction mechanism through online auction websites and whether they have participated in other experiments or not. Finally, the monitor pays each subject privately in cash.

\subsection{Results}

Aggregate bidding behavior in HG-Baseline and HG-Incentives is presented in Table 5. For each treatment, we computed average and median bids. We also provide measures of the extent of the violation of the experimental budget constraint and the participation constraint. We look at the participation constraint through the number of bids equal to 0 ( $\sharp$ zero bids in the Table). Recall an experimental budget constraint applies to bidding in the HG auction because subject have to pay out-of pocket money (or behave as if they had to) would they win the auction with a bid higher than the earnings from previous parts of the experiment. We look at the budget constraint through the number of bids which are above 
Table 5: Homegrown bidding behavior in real and hypothetical treatments

\begin{tabular}{clccccc||c}
\hline \hline & Round 1 & Round 2 & Round 3 & Round 4 & Round 5 & All rounds \\
\hline \hline \multirow{3}{*}{ HG-Baseline } & Mean bid $(€)$ & 15.36 & 18.19 & 17.33 & 17.38 & 18.90 & 17.43 \\
& Median bid(€) & 16.25 & 20.50 & 19.75 & 19.75 & 20.75 & 19.50 \\
& $\sharp$ zero bids & 0 & 0 & 0 & 0 & 0 & $0(0.0 \%)$ \\
& $\sharp$ bids $>$ gains & 7 & 9 & 8 & 9 & 10 & $43(47.7 \%)$ \\
\hline \hline \multirow{3}{*}{ HG-Incentives } & & & & & & \\
& Mean bid $(€)$ & 3.30 & 2.97 & 3.17 & 3.17 & 2.30 & 2.98 \\
& Median bid $(€)$ & 1.25 & 1.00 & 1.25 & 1.00 & 0.75 & 1.00 \\
& $\sharp$ zero bids & 3 & 5 & 5 & 5 & 6 & $24(26.7 \%)$ \\
& $\sharp$ bids $>$ gains & 0 & 0 & 0 & 0 & 0 & $0(0.0 \%)$ \\
Average hyp.-real gap & $465.5 \%$ & $612.5 \%$ & $546.7 \%$ & $548.3 \%$ & $821.7 \%$ & $584.9 \%$ \\
\hline \hline
\end{tabular}

Note. For each treatment and by round (in column), the table summarizes bidding behavior in the HG-experiment: mean and median bid (first two rows for each treatment); number of zero bids (third row) and bids above subject's experimental earnings (fourth row). The last row of the table gives the ratio between average HG-Baseline bids and average HG-Incentives bids.

the subject's earnings $(\sharp$ bids $>$ gains in the Table). Aggregate data exhibit a clear discrepancy between bidding behavior in HG-Baseline and HG-Incentives, i.e. a large discrepancy between hypothetical and real preferences. Mean and median bids in baseline are $€ 17.43$ and $€ 19.5$ as compared to $€ 2.98$ and $€ 1$ in monetary-only ${ }^{23}$ This leads to an average baseline-incentives ratio of $584.9 \%$. The first round of HG auctions gives us an interesting insight because it is more comparable with a survey situation. The gap between hypothetical and real auctions is substantial: on average hypothetical bids are $465.5 \%$ more than when monetary incentives are at stake $(p<.001$ with a bootstrap mean difference test) 24 . The gap is then slightly increasing with rounds taking its highest value in the last round. This is because subjects were aware that there will be five market periods, inducing a typical end game effect.

A closer look at individual behavior allows to identify two driving forces of this difference: First, at the low end of bids no bidder offers zero in the hypothetical treatment while we observe nearly $27 \%$ of bidders bidding zero in the monetary-only treatment. At the high end of the distribution, no subject bid so high that he or she took the chance of paying out of his/her pocket to adopt a dolphin in the monetary incentives. In contrast, almost half the bids are outside the experimental budget constraint in the HG-Baseline treatment. In particular, $22.2 \%$ of bids equal 30 euros, the highest bid value. A non parametric boostrap proportion test indicates that this proportion is statistically significant when compared to HG-Incentives $p=.020$. As a result, two distinct variations in behavior drive the result: the opting-out of the auction through zero bids when incentives are binding ${ }^{25}$ and the inaccurate willingness

\footnotetext{
${ }^{23}$ Three subjects gave the same bid for each round in HG-Baseline and 7 in HG-Incentives.

${ }^{24}$ The bootsstrap test implemented here is a classic bootrstap $t$-test as observations are independent when only the first round is considered.

${ }^{25}$ In Jacquemet, Joule, Luchini, and Shogren (2011), we provide additional treatments that address specifically opting-out behavior by adding a participation procedure to an HG experimental design. Results indicate that subjects in HG-monetary
} 
Figure 2: Distribution of bids in the baseline, incentives and oath treatments

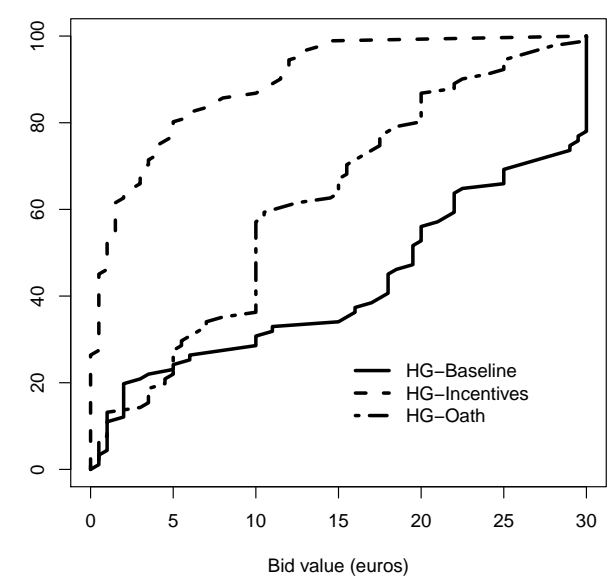

to pay out of ones' own pocket when incentives are dropped. Together, these two differences produce a significant gap between preferences elicited with or without monetary incentives.

We now turn to the way the oath mitigates this gap. In HG-Oath, all subjects but one took an oath prior to participating in the auction 26 Figure 2 provides the empirical distribution of bids from those subjects that participated in the oath treatment, along with the EDF of bids in the baseline and the monetary incentives treatments. Having subjects sign an oath before participating in the auction leads to a distribution that first order dominates the baseline. Quantitative differences can be deduced from Table 6. The mean bidding behavior is $€ 11.46$ after an oath was signed, as compared to $€ 17.43$ in HG-Baseline, i.e., without monetary incentives (Table 5) 27 Behavior in the oath treatment is also different from what we observe in the monetary incentives treatment. EDF of bids in HG-Oath first order dominates EDF of bids in HG-Incentives. The difference is mainly driven by the decrease in the number of zero bids as compared to what we observe when incentives are binding. Comparing Table 6 to Table 5 , the percentage of bids above subject's experimental earnings is $18.9 \%$ in the oath experiment and $47.7 \%$ in the baseline treatment without monetary incentives. The number of violations is more than twice less when subjects take an oath. We observe that only $1.1 \%$ of bids equal 30 euros, the highest bid value. This proportion is significantly lower than that observed in HG-Baseline according to a non parametric bootstrap proportion test $(p=.026)$. It is not statistically different from HG-Incentives $(p=.204)$.

Result 4 In a second price homegrown values auction with hypothetical decisions, asking a bidder to take an explicit oath that pledges him or her to tell the truth and always provide honest answers leads to (i) higher bids than those elicited using incentives and (ii) lower bids than those observed in the baseline.

incentives treatments are more likely to opt-out than bidding a real true zero preference.

${ }^{26}$ Again, the statistical analysis is conducted on the whole sample. Results are similar when excluding the subject who did not take the oath (detailed results available on request from the authors).

${ }^{27}$ Four subjects gave the same bid for each round. 
Table 6: Homegrown bidding behavior in the oath treatment

\begin{tabular}{clccccc||c}
\hline \hline & Round 1 & Round 2 & Round 3 & Round 4 & Round 5 & All rounds \\
\hline \hline \multirow{3}{*}{ HG-Oath } & Mean bid $(€)$ & 9.42 & 10.72 & 11.28 & 11.83 & 14.02 & 11.46 \\
& Median bid $(€)$ & 7 & 10 & 10 & 10 & 13 & 10 \\
& $\sharp$ zero bids & 0 & 1 & 0 & 0 & 0 & $1(1.1 \%)$ \\
& $\sharp$ bids $>$ gains & 3 & 2 & 4 & 2 & 6 & $17(18.9 \%)$ \\
Average oath-real gap & $285.5 \%$ & $360.9 \%$ & $356.2 \%$ & $373.2 \%$ & $617.4 \%$ & $384.9 \%$ \\
Average oath-hyp. gap & $61.3 \%$ & $55.9 \%$ & $65.1 \%$ & $68.1 \%$ & $74.1 \%$ & $65.7 \%$ \\
\hline \hline
\end{tabular}

Note. For each round (in column), the table summarizes bidding behavior in the HG-Oath treatment: mean and median bid (first two rows); number of zero bids (third row) and bids above subject's experimental earnings (fourth row). The last two rows give the ratios between the average bids after an oath and: first, the average HG-Baseline bids; second, the average HG-Incentives bids.

Support. We statistically test the difference in mean bids using a two-sample mean difference test based on a non-parametric bootstrap procedure that accounts for potential correlation between the five bids of the same subject and for asymmetry in the empirical distribution of bids. The procedure is based on bootstrapping subjects and their five bids in the sample (999 times), instead of considering independent bids, i.e., bootstrapping on bids. To account for asymmetry in the empirical distribution, we computed an equal-tail bootstrap $p$-value (see Davidson and MacKinnon, 2006). The decrease in mean behavior as compared to the behavior we observe in the monetary treatment is significant at $p<0.001$ according to this bootstrap test.

We statistically test the decrease in the number of bids above the experimental budget constraint induced by the oath as compared to the behavior in HG-Baseline by a bootstrap proportion test that allows for potential correlation over market periods. The test considers a dichotomous random variable which equals one if the bid is above experimental earnings and zero otherwise. It is based on the same procedure used for the two-sample bootstrap mean test presented above, i.e. bootstrapping subjects in their behavior in the five market periods in the sample (999 times) and take account of asymmetry in the empirical distribution. The decrease in bids outside the experimental budget constraint is significant with $p<0.016$ according to this procedure. In addition, the two-sample mean difference bootstrap test presented above shows that bids elicited in HG-Oath are in average significantly lower than those elicited in HG-Baseline $(p=0.026)$. These results are not likely to be explained either by differences in experimental earnings (mean experimental earnings is $€ 18.88$ in HG-Baseline and $€ 18.13$ in HG-Oath, $p=0.275$ - corresponding on average to 12.2 correct answers out of 20 in the quiz) or differences in debriefing questions: gender $(p=0.516)$, knowing the WWF $(p=0.990)$, knowledge of the WWF wild animal adoption scheme (only one subject was aware of it), level of agreement with WWF actions $(p=0.870)$, past experience with the auction mechanism $(p=0.210)$.

We test the overall significance of Result 4 using a random effects panel Tobit model pooling together data from HG-Baseline, HG-Incentives and HG-Oath. The left-censoring limit is 0 and the right-censoring limit 30. These limits are the bounds of the scroll bar used on the adoption screen 
Table 7: HG bidding behavior - Panel Tobit estimations

\begin{tabular}{lcc}
\hline \hline Variable & $\begin{array}{c}\text { Parameter } \\
\text { estimate }\end{array}$ & P-value \\
\hline \hline Constant term & 16.27 & 0.114 \\
Incentives & -17.67 & 0.000 \\
Oath & -8.34 & 0.001 \\
Round dummies & YES \\
Individual's characteristics & YES \\
\hline \hline$\sigma_{u}$ (sd.) & $6.96(0.755)$ \\
$\sigma_{e}$ (sd.) & $3.95(0.212)$ \\
\hline \hline Log likelihood & \multicolumn{2}{c}{-720.41} \\
\hline \hline
\end{tabular}

Note. Individual random effects Tobit models (random effects are assumed Gaussian), $n=54$ and $T=5$. The endogenous variable is the bid posted. Incentives and Oath are dummy variables. Round (fixed) effects and individual's characteristics are controlled for in the estimation but omitted here - Wald test of joint nullity is 76.99 with $p<0.001$.

when subjects bid their valuation (see Section 5.1). Dummy variables are introduced to control for the HG-Incentives and HG-Oath treatments (HG-Baseline being the referent) as well as total earnings and individual's characteristics ${ }^{28}$ Results are presented in Table 7. As compared to behavior in HG-Baseline, monetary incentives drastically decrease revelation: associated parameter is -16.7 with $p<0.001$. The oath also has a significant impact on bidding behavior as compared to bidding behavior in HG-Baseline: associated parameter is -7.41 with $p=0.002$. This means that, on average, the decrease in bids is twice less in HG-Oath than in HG-Incentives as compared to HG-Baseline when accounting for observed heterogeneity of subjects. This difference is significant with $p<0.001$, i.e. Bids in HG-Incentives do not coincide with bids in HG-Oath.

In short, for the IV treatments, the oath paid off - we could not reject the null hypothesis of sincere bidding in a second price auction under oath. For the homegrown value treatments, in which a gap between revealed and true values exists due to violations in both budget and participation constraints, the oath seems to bind bidders to avoid both: people are less likely to overstate high bids and less likely to understate low bids. We take this as evidence that the oath strengthen the willingness of our subjects to reveal their true preferences for the goods sold in the auctions. In the next three sections, we report the results from complementary treatments that help understand what the oath actually changes on bidders' behavior, and the reasons why it happens.

\footnotetext{
${ }^{28}$ In the model, we used only variables with substantial variability. For instance, we excluded "knowledge of WWF wild animal adoption" because only one subject was aware of it.
} 


\section{Robustness treatments: Commitment of trained bidders}

Ideally, preference elicitation should be more accurate if bidders have no misconceptions about the operations and procedures of the auction mechanism (see for example Lusk and Shogren, 2007; Shogren, Shin, Hayes, and Kliebenstein, 1994). While straightforward in theory, the second price auction used in our treatments is likely to be unfamiliar to many bidders. In particular, they might not immediately realize that bidding their true preferences is the weakly dominant strategy. The oath, by providing subjects with some information about what they should do in the experiment, i.e. telling the truth 29 might only have an effect on subjects unfamiliar with the mechanism and no effect when subjects are more familiar with the second price auction. We assess the truthfulness of this assumption by introducing a preliminary stage in which subjects learn how to behave in a second price auction. By training via practice rounds, bidders can learn the potential consequences of under- and over-bidding one's preferences for the good.

\subsection{Design of the HG-Training treatments}

We train subjects in the three HG treatments with an additional induced values hypothetical secondprice auction, inserted between the quiz and the homegrown auction (see Table 1). Training auctions are identical to those conducted in the IV-Baseline treatment: the auction is repeated over nine periods, implementing all permutations between private values and the whole demand curve being induced in every period (see Section 4.1). To avoid confounding wealth effects, we chose to run the training auctions under a hypothetical setting - bids are expressed in experimental currency, without conversion into Euros whatever the homegrown treatment that follows. The introduction of an IV-Baseline treatment between the quiz and the homegrown auctions is the only difference between training experiments and those conducted in the previous section. The written instructions are the very same as those used for the IV-Experiment (Section 4.2) and the HG-Experiment (Section 5.2). The only differences between the two sets of auctions is the repetition of the game - nine periods for the IV auction to enhance learning of how auctions work versus a five-period HG auction - and the good sold. The training phase is added to the three treatments presented in the previous section and three new treatments are implemented: HGBaseline+Training, HG-Incentives+Training and HG-Oath+Training. Two sessions, one per treatment, were run at the LEEP.

\subsection{Results}

We look first at the effect of training in HG-Baseline+Training and HG-Incentives+Training. EDFs of bids are provided in Figure $3 a$, along with those associated with bidding behavior of untrained bidders observed in HG-Baseline and HG-Incentives. The curves are marginally different for the monetary incentives treatments with a greater but still small effect of training in the baseline treatments. Here,

\footnotetext{
${ }^{29}$ Recall however that subjects do not know in what the experiment will consist when they take the oath.
} 
Figure 3: Distribution of bids from trained and untrained bidders

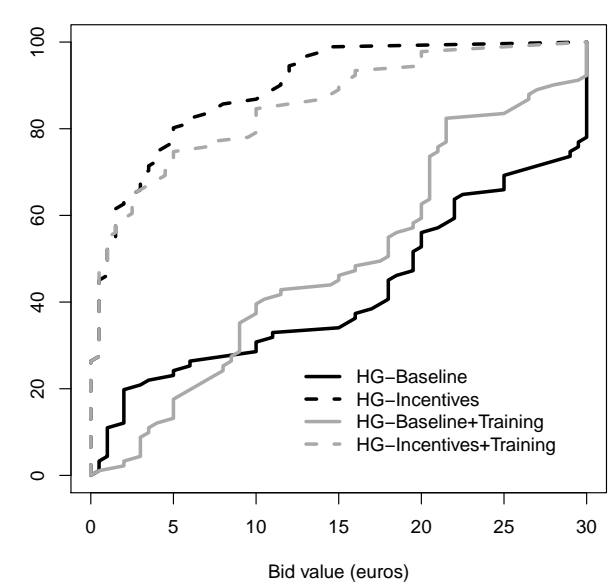

(a) Baseline and Monetary incentives

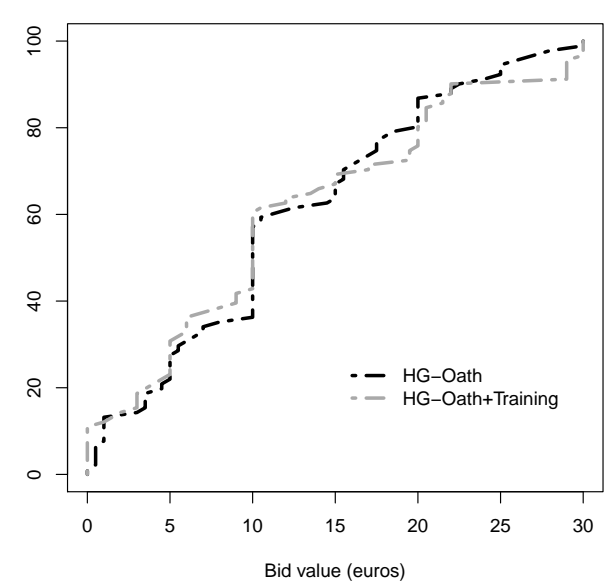

(b) Oath

training seems to increase low bids but decrease higher bids. Comparing Table 8 to Table 5 confirm that training marginally affects bidding behavior. In the baseline, the number of bids above experimental earnings is lower with training than without training $(21.1 \%$ of bids compared to $47.7 \%, p=0.056)$. This in particular leads bidders to bid on average less (€15.31) than in HG-Baseline (€17.43). With incentives, trained bidders bid more (mean is $€ 4.23$ ) than untrained ones (mean is $€ 2.98$ ) ${ }^{30}$

We now turn to the effect of training combined with an oath. As in HG-Oath, we found that subjects expressed no reluctance to take the oath. Again, all subjects but one took an oath prior to participating in the auction (94.5\% acceptance rate) 31 EDFs of bidding behavior are presented in Figure $3 \mathrm{~b}$. The two curves are almost indistinguishable, suggesting that in oath treatments training subjects with respect to the auction mechanism has no effect. Summary statistics on aggregate bidding behavior presented in Table 8 confirm this finding: the mean bid for all rounds is $€ 11.51$ as compared to $€ 11.46$ in the oath treatment without training (see Table 6). The difference in the average values we elicit is due to much less violations of the participation constraint as compared to the one observed in HG-Incentives+Training (from $27 \%$ to zero) and a few less violations of the experimental budget constraint as compared to the one we observe in HG-Baseline+Training (from $21 \%$ to $18 \%, p=0.370$ ).

Result 5 The effect of the oath on bidders is observationally the same whether bidders are trained or not.

Support. As expected given the observed EDFs, the differences as regards training are not significant: the $\mathrm{p}$-value of our two-sample bootstrap mean difference test is $p=0.494$ for HG-Baseline against

\footnotetext{
${ }^{30}$ We only sum up here the main features of these benchmark treatments for comparison purpose. Those results are analyzed in more detail in Jacquemet, James, Luchini, and Shogren (2011).

${ }^{31}$ The statistical analysis is conducted on the whole sample. Results are similar when excluding the subject who did not take the oath (detailed results available on request from the authors).
} 
Table 8: Homegrown bidding behavior after (IV) training

\begin{tabular}{|c|c|c|c|c|c|c|c|}
\hline & & Round 1 & Round 2 & Round 3 & Round 4 & Round 5 & All rounds \\
\hline & Mean bid $(€)$ & 14.61 & 15.25 & 14.41 & 16.72 & 15.58 & 15.31 \\
\hline HG-Baseline & Median bid $(€)$ & 13.25 & 18.25 & 16.75 & 19.75 & 14.75 & 17.75 \\
\hline \multirow{3}{*}{ +Training } & $\sharp$ zero bids & 0 & 0 & 0 & 0 & 0 & $0(0.0 \%)$ \\
\hline & $\sharp$ bids $>$ gains & 3 & 4 & 3 & 6 & 3 & $19(21.1 \%)$ \\
\hline & Mean bid $(€)$ & 3.33 & 5.08 & 4.42 & 4.17 & 4.17 & 4.23 \\
\hline HG-Incentives & Median bid $(€)$ & 0.75 & 0.75 & 1.25 & 0.75 & 0.75 & 1.00 \\
\hline \multirow[t]{2}{*}{ +Training } & $\sharp$ zero bids & 5 & 4 & 5 & 5 & 5 & $24(26.7 \%)$ \\
\hline & $\sharp$ bids $>$ gains & 0 & 0 & 0 & 0 & 0 & $0(0.0 \%)$ \\
\hline \multicolumn{2}{|c|}{ Average hyp.-real gap } & $438.7 \%$ & $300.2 \%$ & $326.0 \%$ & $401.0 \%$ & $373.6 \%$ & $361.9 \%$ \\
\hline \multirow{4}{*}{$\begin{array}{l}\text { HG-Oath } \\
+ \text { Training }\end{array}$} & Mean bid $(€)$ & 10.86 & 10.97 & 11.25 & 12.00 & 12.17 & 11.51 \\
\hline & Median bid $(€)$ & 10.00 & 10.00 & 10.00 & 10.00 & 10.00 & 10.00 \\
\hline & $\sharp$ zero bids & 0 & 0 & 0 & 0 & 0 & $0(0.0 \%)$ \\
\hline & $\sharp$ bids $>$ gains & 3 & 3 & 3 & 3 & 4 & $16(17.8 \%)$ \\
\hline \multirow{2}{*}{\multicolumn{2}{|c|}{$\begin{array}{l}\text { Average oath-real gap } \\
\text { Average oath-hyp. gap }\end{array}$}} & $326.1 \%$ & $215.9 \%$ & $254.5 \%$ & $287.8 \%$ & $291.8 \%$ & $272.1 \%$ \\
\hline & & $74.3 \%$ & $71.9 \%$ & $78.1 \%$ & $71.8 \%$ & $78.1 \%$ & $75.2 \%$ \\
\hline
\end{tabular}

Note. For each Treatment and round (in column), the table summarizes bidding behavior in the HG-experiment for trained subjects: mean and median bid (first two rows for each treatment); number of zero bids (third row) and bids above subject's experimental earnings (fourth row). The last row of the upper part provides the ratio between the average bids in HG-Baseline + Training and the average bids in HG-Incentives + Training. The last two rows of the lower part give the ratios between the average bids after in HG-Oath+Training and: first, the average HG-Baseline+Training bids; second the average HG-Incentives+Training bids.

HG-Baseline+Training; $p=0.476$ for HG-Incentives against HG-Incentives+Training and $p=0.980$ for HG-Oath against HG-Oath+Training.

In summary, Result 4 still holds when training bidders with non-binding IV auctions before bidding in the HG auctions. Even when subjects are familiar with the mechanism, oath induces a decrease in average bidding behavior as compared to baseline and an increase in bids as compared to when monetary incentives are at stake ${ }^{32}$ We now turn to experimental investigations about what exactly the oath changes in the way subjects decide on their bid, and the reasons why it happens.

\section{Does the oath reduce to a demand effect?}

An alternative view of our results is that the oath induces subjects to provide their true value because of a demand effect - in the sense that they comply with the request contained in the oath - rather than

\footnotetext{
${ }^{32}$ The $\mathrm{p}$-value of a one-sided mean difference bootstrap test of a decrease in HG-Oath+Training is $p=0.036$ against HG-Baseline and $p=0.089$ against HG-Baseline+Training; the p-value of a one-sided mean difference bootstrap test of an increase in HG-Oath+Training is $p<0.001$ against HG-Incentives and $p=0.004$ against HG-Incentives + Training.
} 
thanks to a commitment of subjects to tell the truth. In this section, we disentangle between the two based on new experiments aimed at contrasting the preference elicited between having people taking an oath versus an exhortation on the importance of accurate reporting. Such exhortation procedure is commonly known in the preference elicitation literature under the name of "Cheap Talk Scripts" (see the initial paper by Cummings and Taylor, 1999). Cheap talk scripts tell subjects that there is a difference between what people say and do. The existing evidence is rather mixed. Telling bidders that they promise more than they deliver induces a decline in their bids, unless this is not said with enough force (see List and Gallet, 2001). The effectiveness of such an exhortation is greater for larger bids and more inexperienced subjects. In contrast, more neutral cheap talk scripts that tell bidders their promises differ from their actions induces an increase in hypothetical bids, which exacerbates the bias (see Aadland and Caplan, 2003, 2006). As a conservative test of our results, we focus on the first kind of script, i.e. we give subjects extensive information on the size and the sign of the bias and exhort them to avoid it.

\subsection{Design of the Cheap-Talk experiment}

We introduce explicit exhortations about the importance of telling the truth as a new treatment variable. The design of this experiment follows Jacquemet, James, Luchini, and Shogren (2011). Before the HG auctions take place, the instructions conclude with a text highlighting the hypothetical bias generally observed in preference elicitation literature. Our script is an adaptation to the case of a second price auction of the cheap talk script proposed by Cummings and Taylor (1999) (see the Appendix).

The cheap talk exhortation is the only change in the experimental instructions and procedures. Once all instructions, including the cheap talk script, have been read aloud, questions are privately answered and the experiment starts. Two sessions (involving 18 subjects each) were run in the LEEP: the baseline homegrown auction described in Section 5.1 coupled with Cheap talk (HG-CheapTalk) and the same treatment but where subjects are first asked to take an oath (HG-Oath+CheapTalk). In the session, all subjects agreed to do so.

\subsection{Results}

Table 9 summarizes the aggregate data on bidding behavior in the cheap talk treatments. Recall one goal of cheap talk is to get bidders to appreciate the idea that they should make bids as if their experimental budget constraint is binding. In our experiment, this means we want to count how many bidders submit a bid that exceeds their experimental budget constraint (which would imply an out-of-pocket payment if they win the auction). The data suggest two results: (i) when considered in isolation, cheap talk and the oath worked about the same in reducing out-of-pocket bidding relative to the baseline - 13 and 17 bids relative to 43 bids. But (ii) when combined together in the cheap talk/oath treatment, out-of-pocket bids drop to 1 relative to 43 bids, this bid being less than 30 euros. None of the subjects bid the highest bid value in HG-Oath+CheapTalk. Cheap talk and the oath appear to complement each other. 
Table 9: Homegrown bidding behavior after oath and/or cheap talk

\begin{tabular}{|c|c|c|c|c|c|c|c|}
\hline & & Round 1 & Round 2 & Round 3 & Round 4 & Round 5 & All rounds \\
\hline \multirow{4}{*}{ HG-CheapTalk } & Mean bid $(€)$ & 9.13 & 8.08 & 9.50 & 8.97 & 11.02 & 9.34 \\
\hline & Median bid $(€)$ & 5.50 & 5.00 & 6.00 & 5.50 & 6.75 & 5.75 \\
\hline & $\sharp$ zero bids & 0 & 0 & 0 & 0 & 0 & $0(0.0 \%)$ \\
\hline & $\sharp$ bids $>$ gains & 3 & 2 & 3 & 2 & 3 & $13(14.4 \%)$ \\
\hline \multirow{2}{*}{\multicolumn{2}{|c|}{$\begin{array}{l}\text { Average CheapTalk-real gap } \\
\text { Average CheapTalk-hyp. gap }\end{array}$}} & $276.7 \%$ & $272.1 \%$ & $479.1 \%$ & $313.4 \%$ & & \\
\hline & & $59.4 \%$ & $44.4 \%$ & $54.8 \%$ & $51.6 \%$ & $58.3 \%$ & $53.6 \%$ \\
\hline \multirow{4}{*}{$\begin{array}{l}\text { HG-Oath } \\
+ \text { CheapTalk }\end{array}$} & Mean bid $(€)$ & 6.31 & 5.75 & 7.50 & 7.33 & 8.08 & 6.99 \\
\hline & Median bid $(€)$ & 5.00 & 5.00 & 6.25 & 6.25 & 7.75 & 5.75 \\
\hline & $\sharp$ zero bids & 0 & 1 & 0 & 1 & 0 & $2(0.02 \%)$ \\
\hline & $\sharp$ bids $>$ gains & 0 & 0 & 1 & 0 & 0 & $1(0.01 \%)$ \\
\hline \multirow{2}{*}{\multicolumn{2}{|c|}{$\begin{array}{l}\text { Average CheapTalk-real gap } \\
\text { Average CheapTalk-hyp. gap }\end{array}$}} & $191.2 \%$ & $193.6 \%$ & $236.6 \%$ & $231.2 \%$ & $351.3 \%$ & $234.6 \%$ \\
\hline & & $41.1 \%$ & $31.6 \%$ & $43.3 \%$ & $42.2 \%$ & $42.8 \%$ & $40.1 \%$ \\
\hline
\end{tabular}

Note. For each Treatment and round (in column), the table summarizes bidding behavior in the HG-Experiment involving a cheap talk script: mean and median bid (first two rows for each treatment); number of zero bids (third row) and bids above subject's experimental earnings (fourth row). The last two rows of the lower part give: first, the ratios between the average bids in HG-Oath+CheapTalk and the average bids in HG-Incentives+CheapTalk bids ; second, the ratios between the average bids in HG-Oath+CheapTalk and the average bids in HG-Baseline+CheapTalk.

Figure 4 provides a more detailed description of behavior through the empirical distribution function of bids posted in each treatment. We derive three observations from the $2 \times 2$ comparison of the demand functions elicited according to whether a cheap talk script informs subjects before the auction, and whether subjects sign an oath. First, when used alone, the oath disciplines the upper end of the bid distribution observed in HG-Baseline - having subjects sign an oath leaves almost unchanged the lower end (bids less than 10 Euros) of the bid distribution as compared to HG-Baseline, but sharply moves upwards the upper end of the distribution. So, without any indication of what the expected behavior is, an important fraction of the subjects change their bidding strategy as the result of signing an oath to tell the truth. Second, when used alone, the cheap talk script disciplined some of the lowest bids observed in HG-Baseline - the EDF of bids in HG-CheapTalk dominates the one observed in HG-Baseline, but is similar to the EDF of bids in HG-Oath above 10 Euros. When explicitly told the behavior we expect from them, some subjects do change their bidding strategy to comply with our request to report accurate values. Last, combining the oath with the cheap talk script improves bidding behavior as compared to all other settings - the EDF of bids in HG-Oath+CheapTalk first order dominates all other distributions. Oath combined with cheap talk improves elicitation along the lower end of the demand function as compared to oath alone, long the upper end of the demand function as compared to cheap talk alone and along the whole demand function as compared to the Baseline. Overall, the inflexion in the bid distribution and the implementation of the experimental budget constraint result in a drop in the average bid from $€ 17.43$ in HG-Baseline to $€ 6.99$ in HG-Oath+CheapTalk. We also observe that all bids but 
Figure 4: Distribution of bids in Cheap Talk treatments

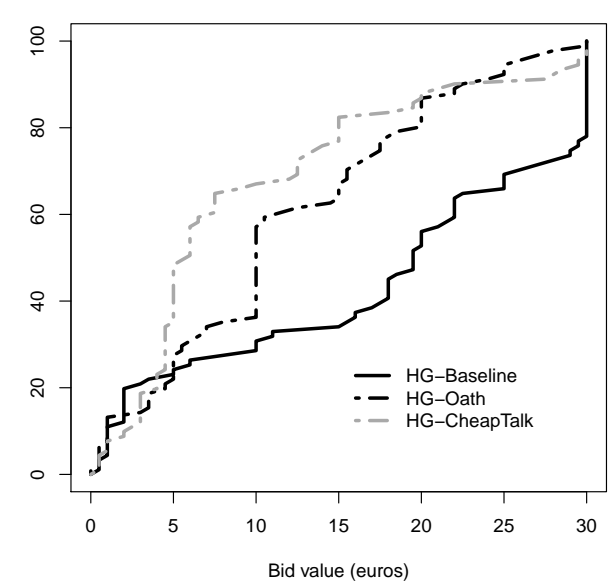

(a) Marginal performance

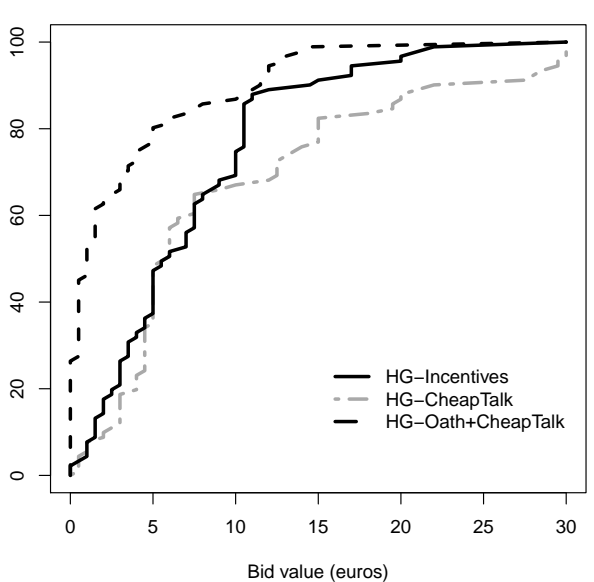

(b) Performance of the combination

one are below experimental earnings in HG-Oath + CheapTalk.

Result 6 Oath combined with cheap talk improves elicitation along (i) the lower end of the demand function as compared to oath alone, (ii) the upper end of the demand function as compared to cheap talk alone, and (iii) the whole demand function as compared to the Baseline.

Support. Based on the mean difference and proportion bootstrap tests described above, we compare behavior in HG-Oath + CheapTalk with bidding behavior in other treatments. First, the mean bid is significantly lower in HG-Oath+CheapTalk as compared to HG-Oath $(p=0.022)$ but not significantly different from HG-CheapTalk $(p=0.244)$ - although mean bidding behavior in HG-CheapTalk in not different from mean bidding behavior in HG-Oath $(p=0.369)$. Second, when subjects take an oath without any exhortation on the importance of accurate reporting (HG-Oath), we observe a significant decrease of the number of bids above experimental earnings as compared to HG-Baseline $(p=0.016)$ but still significantly different from zero as in HG-Incentives $(p=0.023)$. This is also true in HGCheapTalk: number of bids is significantly lower than in HG-Baseline $(p=0.008)$. The number of violations is however still significantly different from zero $(p=0.061)$. When combined with a cheap talk script, the oath reduces the number of bids above experimental earnings as compared to HG-Baseline $(p<0.0001)$, oath alone $(p=0.026)$ and cheap talk only $(p=0.081)$. What is new is that we cannot now reject the null of no violation of the experimental budget constraint, i.e. number of bids above experimental earnings not different from zero $(p=0.119)$. The number of bids that equal the highest bid value is now zero and the change is significant when compared to HG-Baseline $(p=.014)$.

To sum up, cheap talk overcomes a bidder's lack of experience with the good that makes some people think they are telling the truth when in actuality they are not. But it is the Oath, not cheap talk 
warnings, that increases the odds of truth-telling. Both the oath and the cheap talk procedure focus a person's attention on the task at hand. Unlike the oath, cheap talk is informative, providing information on how other people behave, and does not rely on any kind of commitment from subjects. In contrast, the oath induces each person to comply with their signed statement - which is to tell the truth. Those differences in the revelation devices are in line with observed behavior: while cheap talk helps subjects to better identify what their preferences are, the oath seems to induce more of them to truthfully reveal it 33

\section{Why the oath works: an experimental appraisal of behavioral mo- tives}

Our treatments suggest the oath pushes bidding behavior towards more truth telling behavior. Subjects seem more willing to reveal their true preferences. We now discuss two behavioral models that rationalize this effect: (i) cost of lying, an intrinsic preference to keep one's word (in psychology this is a selfattribution process), and (ii) guilt aversion. We consider a companion treatment helps disentangle these two behavioral models.

\subsection{Insight from psychology and behavioral economics}

First, the cost of lying arises from breaking a commitment. In social psychology, commitment is the result of a self-attribution process: people infer their attitudes from their own behavior (Bem, 1972, Kiesler, Nisbett, and Zanna, 1969) 34 This means people deduce from past behavior that they are the "kind of person [...] who does this sort of thing" (Freedman and Fraser, 1966b, p.101), and are more likely to take an action which shares similarities with the initial behavior. The oath acts as a commitment device because it puts people in the mind frame about the next action. When bidding in the auction, a person may consider himself as someone who bids sincerely because they have already signed the oath that commits them to "tell the truth".

This interpretation from social psychology is related to the debate on pre-play communication in experimental games. Evidence suggests promises exchanged freely before the game starts enhance cooperative behavior. Ellingsen and Johannesson (2004) argue communication and promises create commitment because people prefer consistency. We have a taste for keeping our word; otherwise, we pay an internal cost for lying. In a trust game, they find aversion to inequality and the cost of lying strengthens the credibility of promises. This implies for our experiments that the oath can impose a psychological cost on lying if bidders do not bid their induced value after having signed the oath.

\footnotetext{
${ }^{33}$ It can also be argued that cheap talk has a "priming" component. Cheap talk however contains explicit warnings whereas priming is implicit.

${ }^{34}$ The self-attribution argument is central to self-signaling models in economics. Here agents derive utility from the outcome of actions, outcome utility, and they derive diagnostic utility from the information the action reveals about an underlying trait in themselves (see for instance Bodner and Prelec, 2001).
} 
Figure 5: Distribution of bids after a meaningful oath

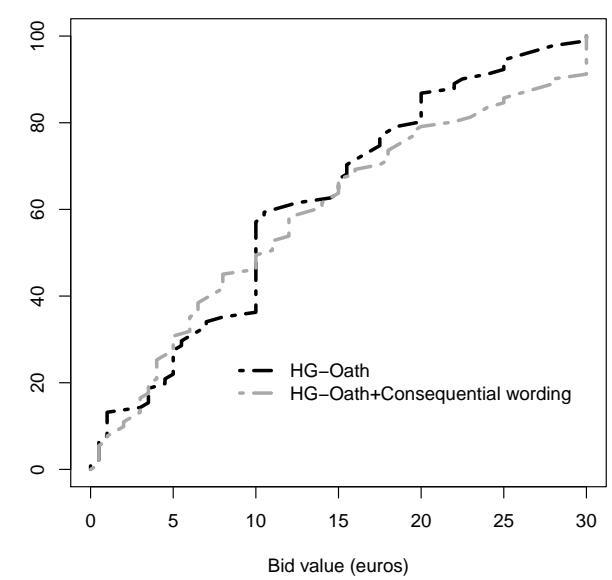

Second, an alternative explanation is guilt aversion, which is experienced by one who fails to meet the expectations of others (Dufwenberg and Gneezy, 2000; Battigalli and Dufwenberg, 2007). Avoiding guilt could explain why people keep promises in trust games (Charness and Dufwenberg, 2006). In our case, this implies bidders bid sincerely because they do not want to disappoint the monitor.

\subsection{Guilt-enhancing oath}

A key difference between commitment-based explanations and guilt aversion is that the guilt induces a positive correlation between the cost imposed on others by the lie and the incentives to tell the truth. We consider a companion treatment which aims to enhance the feeling of guilt associated with violating the oath signed in the HG experiment. We design a new oath treatment that stresses how lying would affect the research program: dishonest answers will bias the results (because this is "what we observed in previous experimental studies").

Our new experiment is identical to HG-Oath except we make the oath more meaningful for the subjects. This HG-Oath+Meaningful treatment adds three extra sentences to how we describe the oath. When they arrive at the desk, the monitor explains how within this type of experiment, researchers have observed people tend to provide insincere answers and which would bias our results (note nothing is said about what the experiments will be about). The oath is introduced to the subject as a way to avoid such undesirable results; we still stress that signing the oath is neither mandatory nor will affect experimental earnings. If the oath is signed, the experimenter adds "good, now I'm relieved", and the experiment runs according to the procedure used in the baseline treatment.

First, all subjects agreed to take an oath prior to the auction. This result, combined with the acceptance rates obtained in HG-Oath, HG-Oath+Training and HG-Oath+Cheaptalk, leads to an acceptance rate of $97.2 \%$ overall -subjects in all four treatments expressed no concern for being put under pressure in the oath procedure. Second, Figure 5 shows the EDF of bids in HG-Oath+Meaningful relative to 
Table 10: Homegrown bidding behavior under a meaningful oath

\begin{tabular}{llccccc||c}
\hline \hline & Round 1 & Round 2 & Round 3 & Round 4 & Round 5 & All rounds \\
\hline \hline \multirow{2}{*}{ HG-Oath } & Mean bid $(€)$ & 9.94 & 12.56 & 13.50 & 12.63 & 13.00 & 12.33 \\
+ Meaningful & Median bid $(€)$ & 6.50 & 10.50 & 12.25 & 12.50 & 12.00 & 10.50 \\
& $\sharp$ zero bids & 0 & 0 & 0 & 0 & 0 & $0(0.0 \%)$ \\
& $\sharp$ bids $>$ gains & 3 & 3 & 5 & 4 & 5 & $20(22.2 \%)$ \\
& & & & & & \\
Average oath-real gap & $301.2 \%$ & $422.9 \%$ & $425.9 \%$ & $398.4 \%$ & $565.2 \%$ & $413.7 \%$ \\
Average oath-hyp. gap & $64.7 \%$ & $65.5 \%$ & $77.9 \%$ & $72.7 \%$ & $68.8 \%$ & $70.7 \%$ \\
\hline \hline
\end{tabular}

Note. For each round (in column), the table provides bidding behavior in HG-Oath+Meaningful: mean and median bid (first two rows); number of zero bids (third row) and bids above subject's experimental earnings (fourth row). The last two rows of the table gives the ratios between the average bids in this treatment and: first, HG-Baseline bids; second, HG-Incentives bids.

the EDF of bids in HG-Oath. EDFs do not exhibit clear differences, which suggests making the oath more meaningful does not add any further effect to the standard procedure. A comparison of mean bidding behavior confirms this finding. Table 10 presents summary statistics on bidding behavior in HG-Oath+Meaningful. Average behavior is unchanged by making the oath more meaningful: mean bid is $€ 12.33$ in HG-Oath+Meaningful and $€ 11.46$ in HG-Oath. It is interesting to note however that mean bid increases slightly after the first round and stabilizes afterwards. This trend in bidding behavior under oath seems to be common to all our oath treatments. In HG-Oath, mean bid increases from $€ 9.42$ in the first round to $€ 11.83$ in the fourth round and to $€ 14.02$ in the last round. When the oath is combined with training, mean bid starts at $€ 10.86$ and ends at $€ 12.17$. In HG-Oath+CheapTalk, in the first round mean bid is $€ 6.31$ and $€ 8.08$ in the fifth round. Although the oath is still effective in all these treatments, it seems that its effect tends to fade out slightly with rounds. Our oath procedure is independent of the experimental auctions. Subjects take an oath outside the experimental lab, thus without knowing what would happen next, whereas cheap talk and training, for instance, are part of the experimental auctions. It would be interesting to see if a reminder that the subject has taken an oath would be effective to mitigate the apparent decrease of effectiveness of the oath 35

Nonetheless, it can be said that the oath is an form of commitment binding a person to tell the truth. The results 7 suggest that adding explicit warnings about the consequences of lying for the research (and consequently for the monitor, identified as a member of the research team), "our results would be biased", does not make any significant difference. Given the theory of commitment, our results suggest the plausible explanation that people behave differently under oath because the oath commits them to tell the truth, not because they dislike the consequences for others of lies.

\footnotetext{
${ }^{35}$ In some commitment experiments, subjects are reminded about having performed the initial request when asked to perform the target request (see Joule and Beauvois, 1998).
} 
Result 7 Making the oath more meaningfull for subjects is neutral on the oath performance.

Support. Mean bidding behavior is not significantly different from mean bidding behavior in the oathonly treatment. The $p$-value from the two-sample mean difference bootstrap test is $p=0.731$.

\section{Summary of the results}

Finally, we run a conditional test to confirm all 7 results by pooling data from all nine $\mathrm{HG}$ treatments in a random effects panel Tobit model. We control for all treatments, interactions between treatments, total earnings, and individual characteristics of bidders. The referent behavior is bidding under in the HG-baseline treatment.

Table 11 supports the main conclusions derived from unconditional statistics run on aggregate bidding behavior. First, the parameter associated with monetary incentives is negative and significant, indicating that subjects bid on average $€ 17.2$ less when monetary incentives are binding than in baseline $(p<$ $0.001)$ ). Second, the dummy variable for oath is significant and negative: subject bid on average $€ 7.1$ less when they take an oath relative to the baseline $(p=0.007)$. Third, the parameter associated with trained bidders is not significant $(p=0.339)$; this also holds for the oath/monetary incentives interaction terms $(p=0.561$ and $p=0.171)$. Fourth, making the oath more meaningful for subjects has no additional effects on bidding behavior $(p=0.590)$.

Fifth, the parameter associated with the use of cheap-talk is negative and significant $(\mathrm{p}=0.002)$; the parameter associated with the interaction effect of oath/cheap talk is not significant $(\mathrm{p}=0.205)$. This indicates the oath combined with cheap talk leads to greater reductions in hypothetical bidding behavior. From the cheap talk and training treatments, we can deduce that oath both improves the ability of subjects to tell the the truth and their willingness to do so. From the addition of wording which makes the oath meaningful for subjects as regards the consequences of their behavior for the revelation procedure, we have evidence that the change in bidding strategy comes from a commitment of subjects to tell the truth, rather than a concern to comply with others expectation.

\section{Conclusion}

The oath is a centuries-old mechanism designed to align internal incentives with social goals. Herein we examine preference elicitation under oath. Based on the social psychology theory of commitment, we examine whether after taking a solemn oath to tell the truth, people are more likely to bid sincerely in induced and homegrown value auctions. For induced value, we find the oath-only treatment induced sincere bidding behavior on average within a second-price auction; the other hypothetical and real treatments did not. For the homegrown values, the oath induced fewer high end bids relative to the hypothetical treatment, and fewer "false zero" bids in the real treatment. Under oath, bidders seem to 
Table 11: HG bidding behavior - Panel Tobit estimations

\begin{tabular}{lrr}
\hline \hline Variable & $\begin{array}{c}\text { Parameter } \\
\text { estimate }\end{array}$ & p-value \\
\hline \hline Constant term & 9.87 & 0.126 \\
Incentives & -17.19 & 0.000 \\
Oath & -7.11 & 0.007 \\
Training & -2.47 & 0.339 \\
Training $\times$ Oath & 2.16 & 0.561 \\
Meaningful & 1.43 & 0.590 \\
Cheap Talk & -7.99 & 0.002 \\
Cheap Talk $\times$ Oath & 4.80 & 0.205 \\
\hline \hline$\sigma_{u}$ (sd.) & $7.37(.51)$ \\
$\sigma_{e}($ sd.) & $3.29(.11)$ \\
\hline \hline Log likelihood & \multicolumn{2}{c}{-2185.96} \\
\hline \hline
\end{tabular}

Note. Individual random effects Tobit models (random effects are assumed Gaussian), $n=162$ and $T=5$. The endogenous variable is the bid posted. Monetary incentives and Oath are dummy variables. Training is introduced as a dummy variable and training effects specific to monetary incentives and oath are controlled by treatment-specific dummy variables. Meaningful procedure is introduced with a dummy variable (and oath is set to one for these data). Round (fixed) effects and individual's characteristics are controlled for in the estimation but omitted here - Wald joint nullity test is 116.58 with $p<0.001$.

commit to sincere bidding by taking the experimental budget constraint and participation constraint more seriously.

Our oath results were robust to additional treatments. Additional training with the auction mechanism did not affect the behavioral operations of the oath. In addition, we run the oath with and without a "cheap talk" script that describes the discrepancy between hypothetical and real values. Our results confirm that while cheap talk helps truthful people to bid in better accordance with their true preferences, it is the oath that increases the odds of truthfulness in the sample. Finally, we examine the oath-as-commitment against a competing idea that bidders bid the truth because they were "averse to guilt". Here our findings on the oath are suggestive; in the homegrown auction we finding that stressing the negative consequences of violating the oath (guilt aversion) did not affect bidding behavior.

We recognize the limits to the oath in stated preference methods. In these testbed experiments, we used the second price auction. The auction offers a high level of experimental control, but has little practicality in public opinion surveys. In a companion paper, we have extended the oath to elicitation mechanisms more frequently used in practice, such as the referendum (Jacquemet, James, Luchini, and Shogren, 2010). In addition, we drew from a limited pool of subjects, which leaves open the question of sample selection. This has long been a generic critique of experimental results (see fo instance, Henrich, Heine, and Norenzayan, 2010). We leave it for future research as to whether our results can be replicated in other contexts, for other cultures, and a broader group of people. Lastly, we appreciate the concern that the oath reduces to a demand effect induced by the experimental context. Our findings suggest 
this is not the case; but future applications in randomized control treatments would be useful to help identify the pros and cons of the oath as a practical element of survey design (see, e.g., Morrison and Brown, 2009) 36

\section{References}

Aadland, D., And A. J. Caplan (2003): "Willingness to Pay for Curbside Recycling with Detection and Mitigation of Hypothetical Bias," American Journal of Agricultural Economics, 85(2), 492-502.

(2006): "Cheap talk reconsidered: New evidence from CVM," Journal of Economic Behavior \& Organization, 60(4), 562-578.

Andreoni, J., And B. D. Bernheim (2009): "Social Image and the 50-50 Norm: A Theoretical and Experimental Analysis of Audience Effects," Econometrica, 77(5), 1607-1636.

Battigalli, P., And M. Dufwenberg (2007): "Guilt in games," American Economic Review, 97, 170-176, Papers and Proceedings.

Beauvois, J.-L., And R.-V. Joule (1996): A radical Dissonance Theory. Taylor \& Francis.

(2002): Petit traité de manipulation à l'usage des honnêtes gens. Presse Universitaires de Grenoble.

BEM, D. (1972): "Self-perception theory," in Advances in experimental social psychology, ed. by L. Berkowitz, vol. 6. Academic Press, New York.

Blumenschein, K., G. C. Blomquist, M. Johannesson, N. Horn, and P. Freeman (2008): "Eliciting Willingness to Pay Without Bias: Evidence from a Field Experiment," Economic Journal, 118(525), 114-137.

Bodner, R., And D. Prelec (2001): "Self-signaling in a neo-Calvinist model of everyday decision making," in Essays in Psychology and Economics, ed. by J. Carillo, and I. Brocas. Oxford University Press.

Boyce, T. E., ANd E. S. Geller (2000): "A Community-Wide Intervention to Improve Pedestrian Safety: Guidelines for Institutionalizing Large-Scale Behavior Change," Environment and Behavior, 32(4), 502-520.

Braham, M., And F. Bolle (2006): "A difficulty with oaths: On trust, trustworthiness, and signalling," European Journal of Law and Economics, 22(3), 219-232.

Brenm, J. (1966): A theory of psychological reactance. Academic Press, New York.

Brocas, I., J. Carrillo, and M. Dewatripont (2003): "Commitment devices under self-control problems: An overview," in The Psychology of Economic Decisions, ed. by I. Brocas, and J. D. Carillo, vol. 2, chap. 4, pp. 49-66. Oxford University Press, Oxford.

Burger, J. M. (1999): "The Foot-in-the-Door Compliance Procedure: A Multiple-Process Analysis and Review," Personality and Social Psychology Review, 3(4), 303-325.

\footnotetext{
${ }^{36}$ Carlsson (2010) designed a contingent valuation survey to include an oath-like procedure. They did not express difficulties in implementing the oath in the survey, which was run in Sweden and China. Although not part of their design, it would be interesting to see how the oath in a CV survey compare to a treatment with monetary incentives.
} 
Carlsson, F. (2010): "Design of Stated Preference Surveys: Is There More to Learn from Behavioral Economics?," Environmental and Resource Economics, 46(2), 167-177.

Charness, G., and M. Dufwenberg (2006): "Promises and Partnership," Econometrica, 74(6), 1579-1601.

Cherry, T., P. Frykblom, J. Shogren, J. List, and M. Sullivan (2004): "Laboratory Testbeds and Non-Market Valuation: The Case of Bidding Behavior in a Second-Price Auction with an Outside Option," Environmental and Resource Economics, 29(3), 285-294.

Cherry, T. L., P. Frykblom, and J. F. Shogren (2002): "Hardnose the Dictator," American Economic Review, 92(4), 1218-1221.

Cialdini, C., J. Bassett, R. Miller, And J. Miller (1978): "Low-ball procedure for producing compliance: Commitment, then cost," Journal of Personality and Social Psychology, 36(5), 463-476.

Cialdini, R., And B. Sagarin (2005): "Interpersonal influence," in Persuasion: Psychological insights and perspectives, ed. by T. Brock, and M. Green, pp. 143-169. Sage Press, Newbury Park, CA.

Cummings, R., D. Brookshire, And W. Schulze (1986): Valuing Environmental Goods: An Assessment of the Contingent Valuation Method. Rowman \& Littlefield Publishers, Savage (MD).

Cummings, R. G., S. Elliott, G. W. Harrison, and J. Murphy (1997): "Are Hypothetical Referenda Incentive Compatible?," Journal of Political Economy, 105(3), 609-621.

Cummings, R. G., And L. O. Taylor (1999): "Unbiased Value Estimates for Environmental Goods: A Cheap Talk Design for the Contingent Valuation Method," American Economic Review, 89(3), 649-665.

Davidson, R., And J. G. MacKinnon (2006): "Bootstrap methods in econometrics," in Palgrave Handbooks of Econometrics, ed. by T. C. Mills, and K. D. Patterson, vol. 1, chap. 23, pp. 812-838. Palgrave Macmillan, Basingstoke.

Dufwenberg, M., And U. Gneezy (2000): "Measuring Beliefs in an Experimental Lost Wallet Game," Games and Economic Behavior, 30, 163-182.

Ehmke, M., J. L. Lusk, AND J. List (2008): "Is Hypothetical Bias a Universal Phenomenon? A Multi-National Investigation," Land economics, 84(3), 489-500.

Ellingsen, T., And M. Johannesson (2004): "Promises, Threats and Fairness," Economic Journal, 114(495), $397-420$.

ElSteR, J. (1977): "Ulysses and the sirens: a theory of imperfect rationality," Social Science Information, 16(5), $469-526$.

Freedman, J. L., AND S. Fraser (1966a): "Compliance without pressure: the foot-in-the-door technique," Journal of Personality and Social Psychology, 4, 195-202.

Freedman, J. L., And S. C. Fraser (1966b): "Compliance without pressure: The foot-in-the-door technique," Journal of Personality and Social Psychology, 4(2), 195-202.

Geller, E. S., M. J. Kalsher, J. R. Rudd, and G. R. Lehman (1989): "Promoting Safety Belt Use on a University Campus: An Integration of Commitment and Incentive Strategies," Journal of Applied Social Psychology, 19(1), 3-19. 
Greiner, B. (2004): "An Online Recruitment System for Economic Experiments.," in Forschung und wissenschaftliches Rechnen 2003. GWDG Bericht 63, ed. by K. Kremer, and V. Macho, pp. 79-93. Ges. für Wiss. Datenverarbeitung, Göttingen.

Guéguen, N., R.-V. Joule, S. Halimi-Falkowicz, A. Pascual, J. Fischer-Lokou, and M. DufourcqBrana (2011): "I'm Free but I'll Comply With Your Request: Generalization and Multidimensional Effects of "Evoking freedoom" Technique," Journal of Applied Social Psychology, Forthcoming.

Guéguen, N., M. Marchand, S. Halimi-Falkowicz, and R.-V. Joule (2011): "The effect of repeating "yes" in a first request on compliance with a later request: the Yes-In-The-Door technique," Mimeo, Working paper, Université de Provence, France.

Henrich, J., S. J. Heine, And A. Norenzayan (2010): "The Weirdest People in the World?," Behavioral and Brain Sciences, 33(2/3), 61-83.

Higgins, E., W. Rhodes, And C. Jones (1977): "Category accessibility and impression formation," Journal of Experimental Social Psychology, 13, 141-154.

Jacquemet, N., A. James, S. Luchini, And J. Shogren (2010): "Referenda under oath," GREQAM WP, $10(15)$.

- (2011): "Social psychology and environmental economics: a new look at ex ante corrections of biased preference evaluation," Environmental \& Resource Economics, 48(3), 411-433.

Jacquemet, N., R.-V. Joule, S. Luchini, And J. Shogren (2009): "Earned Wealth, Engaged Bidders? Evidence from a second price auction," Economics Letters, 105(1), 36-38.

- (2011): "Do people always pay less than they say? Testbed laboratory experiments with IV and HG values," Journal of Public Economic Theory, 13(5), 857-882.

Joule, R. (1998): "Cognitive dissonance theory: A radical view," European Review of Social Psychology, 8, 1-32.

Joule, R., And J. Beauvois (1998): La soumission librement consentie. Presses Universitaires de France, Paris.

Joule, R., F. Bernard, and S. Halimi-Falkowicz (2008): "Promoting ecocitizenship : in favor of binding communication," International Scientific Journal for Alternative Energy and Ecology, 6(62), 214-218.

Joule, R.-V., F. Girandola, and F. Bernard (2007): "How Can People Be Induced to Willingly Change Their Behavior? The Path from Persuasive Communication to Binding Communication," Social and Personality Psychology Compass, 1(1), 493-505.

Kagel, J. (1995): "Auctions: A Survey of Experimental Research," in Handbook of Experimental Economics, ed. by J. Kagel, and A. Roth, pp. 501-585. Princeton University Press, Princeton.

Katzev, R., And T. WAng (1994): "Can commitment change behavior ? A case study of environmental actions," Journal of Social Behavior and Personality, 9, 13-26.

KiEsLeR, C. (1971): The psychology of commitment. Experiments liking behavior to belief. Academic Press, New York. 
Kiesler, C., R. Nisbett, And M. P. Zanna (1969): "On inferring one's beliefs from one's behavior," Journal of Personality and Social Psychology, 11(4), 321-327.

Kiesler, C., And J. Sakumura (1966): "A test of a model for commitment," Journal of Personality and Social Psychology, 3(3), 349-353.

Knetsch, J., F.-F. Tang, and R. Thaler (2001): "The endowment effect and repeated market trials: Is the Vickrey auction demand revealing?," Experimental Economics, 4(3), 257-269.

Kolb, B., And I. Whishaw (2009): Fundamentals of Human Neuropsychology. Worth Publishers, New York.

Kulik, J., And P. CARLino (1987): "The effect of verbal commitment and treatment choice on medication compliance in a pediatric setting," Journal of Behavioral Medecine, 10(4), 367-376.

Laffont, J.-J., and D. Martimort (2002): The Theory of Incentives: The Principal-Agent Model, vol. 1. Princeton University Press, Princeton (NJ).

List, J. A., And C. A. Gallet (2001): "What Experimental Protocol Influence Disparities Between Actual and Hypothetical Stated Values?," Environmental and Resource Economics, 20(3), 241-254.

Lusk, J., And J. Shogren (2007): Experimental Auctions: Methods and Applications in Economic and Marketing Research. Cambridge University Press.

Morrison, M., And T. Brown (2009): "Testing the Effectiveness of Certainty Scales, Cheap Talk, and Dissonance-Minimization in Reducing Hypothetical Bias in Contingent Valuation Studies," Environmental and Resource Economics, 44(3), 307-326.

Murphy, J. J., P. G. Allen, T. H. Stevens, and D. Weatherhead (2005): "A Meta-analysis of Hypothetical Bias in Stated Preference Valuation," Environmental and Resource Economics, 30(3), 313-325.

Pallack, M., D. Cook, And J. Sullivan (1980): "Commitment and energy conservation," in Applied Social Psychology Annual, ed. by L. Bickman, pp. 235-253. Beverly Hills, CA: Sage.

Parkhurst, G. M., J. F. Shogren, and D. Dickinson (2004): "Negative Values in Vickrey Auctions," American Journal of Agricultural Economics, 86(1), 222-235.

Pratkanis, A. R. (2007): The science of social influence. Psychological Press, New York.

Schelling, T. (1960): The strategy of conflict. Harvard University Press, Cambridge (MA).

Schlesinger, H. J. (2008): Promises, Oaths, and Vows: On the Psychology of Promising. Analytic Press, New-York (NJ).

Shogren, J. F., M. Margolis, C. Koo, And J. A. List (2001): "A random nth-price auction," Journal of Economic Behavior \& Organization, 46(4), 409-421.

Shogren, J. F., S. Y. Shin, D. J. Hayes, And J. B. Kliebenstein (1994): "Resolving Differences in Willingness to Pay and Willingness to Accept," American Economic Review, 84(1), 255-270.

Smith, V. (1994): "Lightning Rods, Dart Boards, and Contingent Valuation," Natural Resources Journal, 34, $121-152$. 
Vickrey, W. (1961): "Counterspeculation, Auctions, and Competitive Sealed Tenders," Journal of Finance, $16(1), 8-37$.

WANG, T., AND R. KATSEV (1990): "Groupe commitment and resource conservation : two field experiments on promoting recycling," Journal of Applied Social Psychology, 20, 265-275.

Zeiliger, R. (2000): "A presentation of Regate, Internet based Software for Experimental Economics," http://www.gate.cnrs.fr/zeiliger/regate/RegateIntro.ppt, GATE. 


\section{Appendix: Cheap talk script}

"In a recent study, several different groups of people were involved in an auction just like the one you are about to be in. The earnings in Euros were independent from the decisions made during the auction, just as it will be for you. No one had to pay money in case of adoption. With another set of groups with similar people, the earnings in Euros from the experiment did depend on the decision made during the auction. The auction was the very same as the one you're involved in, the only difference being that earnings were deduced from the result of the auction, so the winner of the auction actually had to pay the second highest bid to the WWF for actually adopting a dolphin. What we observed based on those two groups is the donation offered in the auction is in average more than five times higher when earnings are independent from decisions made, as compared to when earnings do depend on decisions.

We call this a "hypothetical bias". Hypothetical bias is the difference that we continually see in the way people propose prices in hypothetical auctions, in which earnings are independent from decisions, as compared to real auctions, in which earnings do depend on decisions.

Now can we get people to think about their decision in a hypothetical auction like they think in a real auction, where if they win the auction they'll really have to pay money? How do we get them to think about what it means to really dig into their pocket and pay money, if in fact they really aren't going to have to do it. Let me tell you why I think that we continually see this hypothetical bias, why people behave differently in a hypothetical auction than they do when the auction is real. I think that when we take decisions in an auction that involves doing something that is basically good - helping people in need, improving en- vironmental quality, or anything else - we care too much about the resulting situation rather the actual payoff this induces. In a hypothetical auction like the one you're involved in, the basic reaction is to think: "sure, I would do this". I really want to offer an high donation and spend money on adopting a dolphin. But when the auction is real, and we would actually have to spend our money if we win the auction, we think a different way. We basically still would like to see good things happen, but when we are faced with the possibility of having to spend money we think about our options: if I spend money on this, that's money I don't have to spend on other things. So we offer a donation that takes into account the limited amount of money we have, accounting for the earnings in Euros that are realized by our decisions.

This is just my opinion, of course, but it's what I think may be going on in hypothetical auctions. So if I were in your shoes I would ask myself: if this were a real auction, and I had to pay the second highest bid to the WWF: what is the actual donation I want to offer? Let me insist on what maybe going on in this hypothetical setting: you may mistakenly state a higher value than the one you would really be prepared to pay in a real setting. This may even happen if you try to overcome the hypothetical bias issue, simply because your mind setting is framed by this hypothetical scenario. This means you may still be influenced by your desire to help the WWF independently of any gains or losses. Please try to overcome this tendency, and take your decision just exactly as you would if you were really going to face the consequences of your decision: which is to spend money on the donation if you win the auction. Please keep this in mind in our auction." 